UNIVERSIDADE DE SÃO PAULO

Instituto de Astronomia, Geofísica e C. Atmosféricas

\title{
UM ESTUDO SOBRE O DESEQUILÍBRIO RADIOATIVO DA SÉRIE DO URÂNIO EM
}

DANILLO SILVA DE OLIVEIRA

SÃO PAULO - SP

2006 


\section{Danillo Silva de Oliveira}

\section{Um estudo sobre o desequilíbrio radioativo da série do urânio em amostras de solo}

Orientador: Dr. Fernando Brenha Ribeiro

Dissertação apresentada ao Instituto de Astronomia, Geofísica e Ciências Atmosféricas da Universidade de São Paulo para a obtenção do título de Mestre em Ciências em Geofísica. 
Oliveira, Danillo Silva de.

Um estudo sobre o desequilíbrio radioativo da série do urânio em amostras de solo. / Danillo Silva de Oliveira; Orientador: Dr. Fernando Brenha Ribeiro. - São Paulo, 2006.

$79 f$. ffig.

Dissertação (Mestrado - Pós-Graduação em Geofísica. Área de concentração: Geofísica Nuclear.) - Instituto de Astronomia, Geofísica e Ciências Atmosféricas da Universidade de São Paulo.

1.Rádio 2.Chumbo radioativo 3.Radioatividade do solo. 4.Séries radioativas. I. Título. 
Dedico este trabalho à minha mãe e à minha irmã. 


\section{Agradecimentos}

Ao Prof. Dr. Fernando Brenha Ribeiro pela amizade, atenção, confiança, orientação e enorme paciência.

À Prof ${ }^{\mathrm{a}}$ Leila Soares Marques pelo acompanhamento e colaboração.

Ao Prof. Francisco Yukio Hiodo pela atenção e colaboração na pesquisa.

Ao Jardim Botânico do Estado de São Paulo por permitir a coleta do solo.

Ao Ernande pela grande ajuda durante a coleta das amostras.

Ao Prof. Joel B. Sígolo pela descrição das amostras.

À Rosana Nunes e ao Roberto Keiji pela colaboração no laboratório.

À Teca, Virgínia e Magda, secretárias do departamento de geofísica, e à Rose, secretária seção da pós-graduação do instituto, pela atenção.

Ao Edilson, Marco e Leonardo, da seção de informática, sempre dispostos a ajudar quando preciso.

Aos amigos Wanderson, Fábio Lucas, Dionísio, Everton, Marcelo Bianchi, Marcelo Peres, Alanna, Welintom, Alexandre Lago, Alexandre Lopes, Robsom, Marcos, Igor, Claúdia, Daniele, Selma, Francisca, Deborah, Manuelle, Érika, Ahmad, Frankiln.

Agradeço à meus pais, Célia e Francisco, minha querida irmã, Danielle, aos meus irmãos, Douglas e Lucas, à minhas tias, tios e ao amigo Arimar, que sempre me apoiam em minhas decisões.

À Fundação de Amparo à Pesquisa do Estado de São Paulo (FAPESP), processo 2004/03175-7, pelo apoio financeiro. 


\section{Resumo}

OLIVEIRA, D. S. Um estudo sobre o desequilíbrio radioativo da série do urânio em amostras de solo. 2006. 79 f. Dissertação - Instituto de Astronomia, Geofísica e C. Atmosféricas, Universidade de São Paulo, São Paulo, 2006.

As atividades específicas do ${ }^{238} \mathrm{U},{ }^{226} \mathrm{Ra},{ }^{210} \mathrm{~Pb},{ }^{232} \mathrm{Th}$ e ${ }^{40} \mathrm{~K}$, foram medidas, utilizando-se a técnica de espectrometria- $\gamma$ de alta resolução, em amostras de solo coletadas em três furos com 2,10 $\mathrm{m}$ de profundidade e feitos com trado manual. $\mathrm{O}$ material amostrado é um latossolo desenvolvido sobre rochas quartzo-feldspáticas. O local da amostragem, no terreno do Instituto de Botânica da Secretaria do Meio Ambiente do Estado de São Paulo, possui uma cobertura vegetal densa que, junto com a camada superficial de solo, não é perturbada desde, pelo menos, 1938. Os 0,60 m superior da camada de solo amostrada correspondem aos horizontes $\mathrm{O}$ e $\mathrm{A}$, enquanto que os 1,50 $\mathrm{m}$ restantes correspondem ao horizonte $B$.

As medidas de atividade específica do ${ }^{210} \mathrm{~Pb}$ foram corrigidas para compensar os efeitos da absorção da radiação- $\gamma$ com $46,5 \mathrm{keV}$ pela matriz de solo. O procedimento de correção baseado na literatura disponível, foi adaptado com o desenvolvimento de equações apropriadas para representar a geometria de detecção em que as medidas foram realizadas.

Os resultados mostram que as atividades específicas do ${ }^{238} \mathrm{U}$ e do ${ }^{226} \mathrm{Ra}$ variam pouco em função da profundidade. O perfil de atividades do ${ }^{238} \mathrm{U}$ parece refletir a distribuição dos minerais de argila no perfil de solo, enquanto que o perfil de atividades do ${ }^{226} \mathrm{Ra}$ apresenta um valor praticamente constante em todo o solo analisado. O perfil de atividades do ${ }^{210} \mathrm{~Pb}$ mostra um leve enriquecimento desse isótopo nos horizontes $\mathrm{O}$ e A em relação ao restante do perfil. Com a exceção dos horizontes mais superficiais, o ${ }^{226} \mathrm{Ra}$ está em desequilíbrio radioativo com o ${ }^{238} \mathrm{U}$ e o solo apresenta razões de atividade ${ }^{226} \mathrm{Ra} /{ }^{238} \mathrm{U}$ da ordem de 0,90 .

O ${ }^{210} \mathrm{~Pb}$ está em desequilíbrio radioativo com o ${ }^{226} \mathrm{Ra}$ sendo que as razões de atividade ${ }^{210} \mathrm{~Pb} /{ }^{226} \mathrm{Ra}$ variam em torno de 0,7 na maior parte do perfil. A atividade 
específica do ${ }^{210} \mathrm{~Pb}$ é inferior à atividade específica do ${ }^{226} \mathrm{Ra}$ em valores que variam de $8 \mathrm{~Bq} / \mathrm{kg}$ a $18 \mathrm{~Bq} / \mathrm{kg}$.

A série do ${ }^{232}$ Th está em equilíbrio radioativo secular em todas as amostras analisadas. As atividades específicas mais baixas do ${ }^{232}$ Th são observadas nos horizontes $\mathrm{O}$ e A. O horizonte $\mathrm{B}$ é enriquecido em ${ }^{232} \mathrm{Th}$ o que reflete a maior concentração de argilas nesse horizonte.

$\mathrm{O}{ }^{40} \mathrm{~K}$ está distribuído de forma irregular ao longo do perfil de solo analisado e apresenta atividades específicas variando desde valores abaixo do limite de detecção do laboratório até $37,8 \mathrm{~Bq} / \mathrm{kg}$.

Palavras-chave: Rádio, chumbo radioativo, radioatividade do solo, séries radioativas. 


\section{Abstract}

\section{OLIVEIRA, D. S. A study on radioactive disequilibrium of the uranium series}

in soil samples. 2006. 79 f. Master thesis - Instituto de Astronomia, Geofísica e C. Atmosféricas, Universidade de São Paulo, São Paulo, 2006.

The specific activities of ${ }^{238} \mathrm{U},{ }^{226} \mathrm{Ra},{ }^{210} \mathrm{~Pb},{ }^{232} \mathrm{Th}$ and ${ }^{40} \mathrm{~K}$ were measured, and the ${ }^{226} \mathrm{Ra} /{ }^{238} \mathrm{U}$ and ${ }^{210} \mathrm{~Pb} /{ }^{226} \mathrm{Ra}$ activity ratios were calculated for samples collected in a $2.10 \mathrm{~m}$ deep soil profile in a preserved area of the São Paulo Botanic Garden. The sampling site is covered by dense vegetation that, together with the upper soil layer, has not been disturbed since, al least, 1938. The upper $0.60 \mathrm{~m}$ of the soil profile corresponds to the $\mathrm{O}$ and $\mathrm{A}$ soil horizons, whereas the remaining $1.50 \mathrm{~m}$ of the profile corresponds to the B horizon.

The ${ }^{210} \mathrm{~Pb}$ specific activity measurements were corrected for the attenuation of the $46.5 \mathrm{keV} \gamma$-radiation by the soil mineral matrix. The attenuation corretion procedure is based on the available literature and was adapted to represent the detection geometry of the measurements.

The results show that the uranium series is in radioactive disequilibrium in most of the sampled soil. The ${ }^{226} \mathrm{Ra} /{ }^{238} \mathrm{U}$ activity ratios vary around 0.9 whereas the ${ }^{210} \mathrm{~Pb} /{ }^{226} \mathrm{Ra}$ activity ratios resulted in a mean value of 0.7 . The unsupported ${ }^{210} \mathrm{~Pb}$ specific activities are between $-8 \mathrm{~Bq} / \mathrm{kg}$ and $-18 \mathrm{~Bq} / \mathrm{kg}$.

The ${ }^{232}$ Th series is in secular radioactive equilibrium in the whole sampled soil layer. The ${ }^{232}$ Th specific activity distribution seems to reflect the concentration of clay minerals in the soil horizon $\mathrm{B}$.

The ${ }^{40} \mathrm{~K}$ radionuclide is irregulary distributed in the whole sampled soil layer and it's specific activities varying from below detection limit to about $37.8 \mathrm{~Bq} / \mathrm{kg}$.

Keywords: soil radioactivity, radium, radioactive lead, radioactive series. 


\section{Sumário}

\section{Agradecimentos}

\section{Resumo}

\section{Abstract}

\section{Lista de Figuras}

\section{Lista de Tabelas}

1 Introdução

2 Informações geológicas dos radionuclídeos da série do urânio, da série do tório e do potássio

2.1 Distribuição do urânio, rádio e tório no solo $\ldots \ldots \ldots$. . . . . . . p. 17

2.2 Escape do ${ }^{222} \mathrm{Rn}$ no solo $\ldots \ldots \ldots \ldots$. . . . . . . . . . . . . . . . . . .

2.3 Distribuição do ${ }^{210} \mathrm{~Pb}$ no solo e na atmosfera . . . . . . . . . . . . p. p.

2.4 Ocorrência do potássio em solos . . . . . . . . . . . . . . . . p. 22

3 Medidas de atividade por espectrometria de raios- $\gamma \quad$ p. 24

3.1 Local de coleta das amostras . . . . . . . . . . . . . . p. 25

3.2 Coleta e descrição das amostras . . . . . . . . . . . . . . p. 26 
3.3 Preparação das amostras $\ldots \ldots \ldots \ldots \ldots \ldots \ldots \ldots$ p. 28

3.4 Padrões de atividade . . . . . . . . . . . . . . . . . . . . . . . . . p. 29

3.5 Cálculo da atividade de elementos $\gamma$-emissores em amostras ambi-

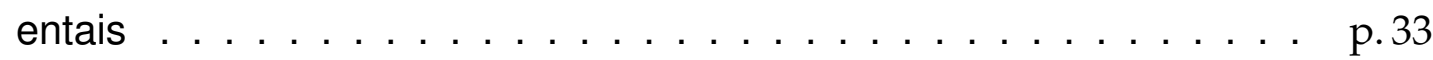

3.6 Radiação de fundo, níveis críticos e limites de detecção qualitativa . . p.35

40 problema da correção do efeito de auto-absorção da radiação- $\gamma$ emitida pelo ${ }^{210} \mathrm{~Pb}$

4.1 Método de correção da auto-absorção na determinação da atividade

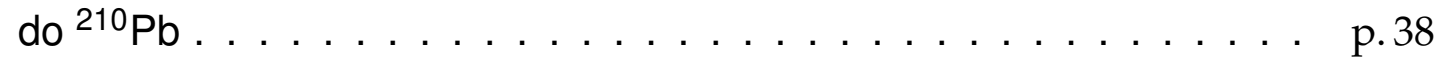

4.1.1 A determinação do coeficiente de atenuação linear . . . . . . p. p.38

4.1.2 A correção do efeito de auto-absorção pela matriz da amostra p.42

4.1.3 Uma estimativa da exatidão do método de correção do efeito de auto-absorção $\ldots \ldots \ldots \ldots \ldots \ldots \ldots \ldots$. . . . . . . .

5 Perfis de atividade dos radionuclídeos das séries do urânio e do tório e atividade do ${ }^{40} \mathrm{~K}$ no solo

5.1 Atividade dos radionuclídeos da série do ${ }^{238} \mathrm{U} \ldots \ldots \ldots \ldots$. . . . . . 49

5.2 Atividade dos radionuclídeos da série do ${ }^{232}$ Th $\ldots \ldots \ldots \ldots$ p. 55

5.3 Atividade do ${ }^{40} \mathrm{~K}$ no solo $\ldots \ldots \ldots \ldots \ldots \ldots \ldots$ p. 58

6 Conclusão $\quad$ p.59

$\begin{array}{ll}\text { Referências Bibliográficas } & \text { p.61 }\end{array}$

Apêndice A - Modelo teórico para a correção do efeito de auto-absorção da radiação do ${ }^{210} \mathrm{~Pb}$ - parte I 
A.1 A equação para estimativa do coeficiente de atenuação linear $\mu$. . p. 65

A.2 A aproximação de fonte linear de radiação . . . . . . . . . . . . . p.69

A.2.1 Fórmulas para o cálculo de $\mathrm{E}_{1}(\mathrm{x}) \ldots \ldots \ldots$ p.73

Apêndice B - Modelo teórico para a correção do efeito de auto-absorção

da radiação do ${ }^{210} \mathrm{~Pb}$ - parte II p.75

B.1 O desenvolvimento da equação $4.5 \ldots \ldots \ldots \ldots$. . . . . . . . . . . . .

B.2 Limitação do método - crítica do modelo . . . . . . . . . . . . . . p.79 


\section{Lista de Figuras}

3.1 Distribuição horizontal dos perfis de amostragem do solo retirado no Instituto de Botânica.

4.1 Geometria para o ângulo sólido de um fóton incidente sobre a superfície do detector quando emitido por um padrão radioativo secundário localizado sobre a amostra de solo .

4.2 Valores da relação $\left(\frac{T}{T}\right)_{\text {calculado, }}$ equação 4.3, em função do coeficiente de atenuação linear $(\mu)$, com $e_{1}=3 \mathrm{~mm}, e_{2}=8,85 \mathrm{~mm}, E=46,00 \mathrm{~mm}$ e $\mathrm{h}=$ $12,00 \mathrm{~mm}$.

4.3 Valores do fator de correção da radiação- $\gamma(G)$, equação 4.5, em função do coeficiente de atenuação linear $(\mu), \operatorname{com~} \mathrm{A}=37,50 \mathrm{~mm}, \mathrm{~B}=45,00 \mathrm{~mm}$ e $E=$ $46,00 \mathrm{~mm}$

5.1 Concentrações de atividades do ${ }^{238} \mathrm{U}(\boldsymbol{\bullet})$, do ${ }^{226} \mathrm{Ra}(\bullet)$ e do ${ }^{210} \mathrm{~Pb}(\bullet)$, expressas em Bq/kg, como função da profundidade do perfil de solo.

5.2 Razões de atividade ${ }^{226} \mathrm{Ra} /{ }^{238} \mathrm{U}(\bullet)$ e ${ }^{210} \mathrm{~Pb} /{ }^{226} \mathrm{Ra}(\boldsymbol{\square})$ como função da profundidade do solo. A barra de erro vertical representa um desvio padrão, e a barra de erro horizontal a metade do intervalo de amostragem. . . . . . . p.53

5.3 Concentração do ${ }^{210} \mathrm{~Pb}$ não-suportado, em Bq/kg, em função da profundidade do solo. A incerteza corresponde a um desvio padrão em torno da média.

5.4 Concentrações de atividade do ${ }^{232}$ Th como função da profundidade do solo. p.56 
A.1 Geometria para o ângulo sólido de um fóton incidente sobre a superfície do detector quando emitido por um padrão radioativo secundário localizado sobre a amostra de solo . . . . . . . . . . . . . . . . p.66

A.2 Modelo geométrico com uma aproximação linear para a radiação primária incidente sobre a superfície do detector. . . . . . . . . . . . . . p.70

B.1 Geometria para o ângulo sólido de um fóton incidente sobre a superfície do detector quando emitido por um padrão radioativo secundário sobre o detector. p.76 


\section{Lista de Tabelas}

3.1 Descrição da camada de solo amostrada no terreno do Jardim Botânico de São Paulo, Parque Estadual das Fontes do Ipiranga (baseado na descrição feita pelo Professor Joel B. Sígolo do Instituto de Geociências da USP). . p.27

3.2 Massa das amostras de solo utilizadas na determinação das atividades nos intervalos de amostragem dos três perfis. . . . . . . . . . . . . . . p. 28

3.3 Características dos padrões secundários utilizados. . . . . . . . . . . . . . p.32

3.4 Coeficientes de atenuação da radiação- $\gamma(\mu / \rho)$, expressos em $\mathrm{cm}^{2} / \mathrm{g}$, para diferentes energias e diferentes materiais. . . . . . . . . . . . p.32

3.5 Contagem da radiação de fundo observada em um período de 48 horas com o padrão estéril LTGSI05 (quartzo moído), níveis críticos e limites de detecção qualitativa correspondentes aos diversos radionuclídeos utilizados.

3.6 Contagem da radiação de fundo, em um período de 48 horas, na região do pico de absorção total do ${ }^{210} \mathrm{~Pb}$ com $46,5 \mathrm{keV}$ de energia, nível crítico e limite de detecção qualitativa nos padrões LGTSIPb e LGTCARPb. . . . . . p.36

4.1 Comparação entre os valores de $\frac{T}{T}$ obtidos através da equação 4.1 (fonte extensa) e através da equação 4.2 (fonte linear). Os parâmetros da fonte extensa são: $\mathrm{a}=7,90 \mathrm{~mm}, \mathrm{~A}=37,50 \mathrm{~mm}, \mathrm{E}=46,00 \mathrm{~mm}, \mathrm{~h}=12,00 \mathrm{~mm}, \mathrm{e}_{1}=$ $3,00 \mathrm{~mm} \mathrm{e} \mathrm{e}_{2}=8,85 \mathrm{~mm} \ldots \ldots \ldots \ldots \ldots \ldots \ldots . \ldots \ldots$. . . . . . . . . . . . . .

4.2 Valores de $\frac{T}{T}, \mu, m, \frac{\mu}{m}$ e $G(\mu)$ medidos nas amostras de solo. . . . . . . p p.46 
4.3 Atividade total do ${ }^{210} \mathrm{~Pb}$, em Bq, estimada pela média das atividades calculados pelo método de correção da auto-absorção com os padrões secundários de ${ }^{210} \mathrm{~Pb}$ nas matrizes de $\mathrm{SiO}_{2}$ e de $\mathrm{CaCO}_{3} \ldots \ldots$. . . . . . . . . p.48

5.1 Atividades individuais do ${ }^{214} \mathrm{~Pb}$, do ${ }^{214} \mathrm{Bi}$, e atividades totais e concentrações de atividade do ${ }^{226} \mathrm{Ra}$ e do ${ }^{238} \mathrm{U}$ nos três perfis de solo. . . . . . . . . . . p. p0

5.2 Atividades totais e concentrações de atividade do ${ }^{210} \mathrm{~Pb}$ observados nas amostras de solo. . . . . . . . . . . . . . . . . . . p. . . . . .

5.3 Atividades individuais do ${ }^{228} \mathrm{Ac}$ e do ${ }^{208} \mathrm{TI}$, atividades totais do ${ }^{228} \mathrm{Ra}$ e do ${ }^{228}$ Th e do ${ }^{232}$ Th nos perfis de solo. . . . . . . . . . . . . . . p.57

5.4 Atividades totais, concentrações de atividade e concentrações em porcentagem de massa do ${ }^{40} \mathrm{~K}$ nas amostras de solo. . . . . . . . . . . . . . p.58

A.1 Coeficientes da equações A.23 e A.24. . . . . . . . . . . . . . . . . p.74

B.1 Energia dos fótons espalhados por efeito Compton como função do ângulo de espalhamento, admitindo um feixe de fótons incidente com 46,5 keV de energia. . . . . . . . . . . . . . . . . . . . . p.79 


\section{Introdução}

O conhecimento da distribuição e dinâmica dos diversos radionuclídeos naturais e de alguns radionuclídeos artificiais nos diferentes tipos de solo representa um aspecto importante do estudo da radioatividade ambiental.

Nas últimas três décadas houve um aumento considerável no interesse sobre o estudo de processos de formação e evolução de solos e de processos de erosão, transporte e deposição de sedimentos recentes. Esse interesse reflete, pelo menos em parte, a preocupação cada vez maior com problemas relacionados com a degradação do meio ambiente, com o aumento da perda da camada de solo e com a contaminação da água e do solo.

Estudos de processos pedogênicos e sedimentares recentes requerem uma cronologia confiável dos diferentes eventos. Com a exceção de situações extremamente favoráveis e pouco usuais, o estabelecimento de uma cronologia para esses processos baseia-se na determinação das atividades de radionuclídeos naturais de meia-vida curta e de radionuclídeos artificiais liberados na atmosfera por ensaios nucleares.

Um segundo aspecto, onde o conhecimento da radioatividade dos solos tem um papel relevante, diz respeito à contínua exposição, da população em geral, à radiação natural de baixa intensidade. Nesse sentido, o comportamento do rádio, em particular do isótopo ${ }^{226} \mathrm{Ra}$ e do seu produto de decaimento, o ${ }^{222} \mathrm{Rn}$, desperta um interesse especial, uma vez que são responsáveis por cerca de $50 \%$ da dose de exposição humana à radiação (NATIONAL COUNCIL ON RADIATION PROTECTION, 1987 apud GREEMAN et al., 1999). O conhecimento do comportamento do rádio nos solos 
também é importante, uma vez que depois do ${ }^{40} \mathrm{~K}$, esse isótopo representa a maior fonte de radiação nos alimentos (LINSALATA, 1994 apud GREEMAN et al., 1999).

O presente trabalho consiste em uma aplicação da técnica de espectrometria- $\gamma$ no estudo da radioatividade de amostras de solo. Em particular, utilizou-se a técnica da espectrometria- $\gamma$ de alta resolução na determinação da atividade do ${ }^{210} \mathrm{~Pb}$. Para essa aplicação foi adaptado um método de correção dos efeitos de absorção da radiação- $\gamma$ com $46,5 \mathrm{keV}$ pela matriz de solo.

A dissertação foi organizada em quatro capítulos, mais introdução, conclusão e dois apêndices. O capítulo 2 apresenta um descrição suscinta do comportamento do urânio, do tório, do rádio e do potássio no solo, além da movimentação no solo e subseqüente escape do gás ${ }^{222} \mathrm{Rn}$ para a atmosfera e da distribuição do ${ }^{210} \mathrm{~Pb}$ no solo e seu comportamento quando presente na atmosfera. O capítulo 3 descreve, em detalhe, o processo de coleta e preparação das amostras, e a técnica utilizada para obtenção das medidas de atividade dos radionuclídeos, além dos respectivos limites de detecção. O capítulo 4 é dedicado ao desenvolvimento do método de correção da auto-absorção da radiação- $\gamma$ com 46,5 keV de energia emitida pelo ${ }^{210} \mathrm{~Pb}$, deduzido em detalhe nos apêndices A e B. O capítulo 5 reúne os resultados obtidos e os discute. 


\section{Informações geológicas dos radionuclídeos da série do urânio, da série do tório e do potássio}

\subsection{Distribuição do urânio, rádio e tório no solo}

A transformação de rochas com teores normais e bem distribuídos nos radionuclídeos urânio e tório pode resultar em materiais de alteração com diferentes distribuições e concentrações desses elementos.

Em geral os solos apresentam valores de radioatividade inferiores aos das rochas, porque, uma vez presente nos solos os radionuclídeos podem ser absorvidos por plantas, ou ter sua concentração lentamente reduzida por processos de lixiviação (GREEMAN; ROSE, 1996; GREEMAN et al., 1999).

As principais anomalias de urânio e de tório são originadas a partir de minerais resistentes contendo urânio e tório, compostos insolúveis de tório, e urânio e tório fixados por oxihidróxidos de ferro, alumínio, manganês e argilas, tais anomalias estão situadas no topo do horizonte B latossólico e as de menor intensidade, mas com maior proporção relativa de urânio livre, fixado principalmente por adsorção, distribuem-se pelo corpo deste horizonte (LANGMUIR, 1978; LANGMUIR; HERMAN, 1980). A retenção de urânio e tório nos perfis de alteração deve-se à estabilidade das fases acessórias, ao urânio e ao tório adsorvido aos produtos do intemperismo, óxidos e argilas, assim como a insolubilidade dos compostos de tório, em níveis mais 
profundos é maior a proporção de urânio livre, adsorvido em argilas e colóides de ferro e alumínio (REBELO; BITTENCOUT; MANTOVANI, 2002). Mesmo materiais intensamente lixiviados mostram uma relativa elevação nos valores de concentração do urânio e do tório, pela acumulação de minerais resistentes e pela associação com as fases óxido, argilosa e carbonosa, principalmente no topo dos horizontes A e B destes solos (REBELO; BITTENCOUT; MANTOVANI, 2002).

A presença de rádio no solo deve-se principalmente aos minerais de urânio e tório presente nos solos e rochas próximas, soluções de rádio e de seus predecessores migrando para camadas profundas do solo, e precipitação do rádio e seus pais que estejam presente na atmosfera (JAWOROWSKI, 1990). Durante o intemperismo e migração da rocha para o solo o rádio pode ser mobilizado em fase particulada, transportado e depositado como loess, sedimentos e solos terciários, entretanto, parte do rádio pode se solubilizar em água e em seguida ser depositado no solo através de ação química ou biológica (IYENGAR, 1990). A alteração também mobiliza o urânio e o rádio para fora da rocha, eles são posteriormente redepositados por adsorção em óxidos ferrosos, matéria orgânica e minerais secundários, por esse motivo espera-se um enriquecimento de urânio e rádio no horizonte $B$ (EDSFELDT, 2001). A concentração do ${ }^{226} \mathrm{Ra}$ no solo varia entre 3,7 a $125,8 \mathrm{~Bq} / \mathrm{kg}$ em áreas normais, os altos valores de concentração são característicos de solos desérticos $(70,3-$ $125,8 \mathrm{~Bq} / \mathrm{kg}$ ), os baixos valores correspondem a solos calcáreos, enquanto que os valores intermediários variam com a composição dos solo (IYENGAR, 1990).

No solo as concentrações do ${ }^{226}$ Ra são, geralmente, diferentes das concentrações do ${ }^{238} U$, esta evidência é um reflexo de suas diferentes mobilidades, o que praticamente não existe quando se trata das concentrações do ${ }^{232} \mathrm{Th}$ e ${ }^{228} \mathrm{Ra}$, a heterogeneidade do solo é o fator que exerce uma maior influência sobre a distribuição irregular do rádio no solo (IYENGAR, 1990; JAWOROWSKI, 1990; GREEMAN et al., 1999). 


\subsection{Escape do ${ }^{222} \mathrm{Rn}$ no solo}

O radônio é um membro intermediário, gasoso, presente nas três séries radioativas naturais e por ser um produto de decaimento do rádio, é produzido em qualquer meio que o contenha. Na natureza ocorre em três diferentes isótopos, o ${ }^{219} \mathrm{Rn}\left(\mathrm{t}_{1 / 2}=\right.$ 3,96 segundos), o ${ }^{220} \mathrm{Rn}\left(\mathrm{t}_{1 / 2}=55,6\right.$ segundos), também conhecido como torônio, e o ${ }^{222} \mathrm{Rn}$ ( $\mathrm{t}_{1 / 2}=3,82$ dias) (MOLINARI; SNODGRASS, 1990; IVANOVICH; HARMON, 1992).

O radônio, por ser um gás inerte, é capaz de se deslocar, por grandes distâncias, dos locais onde é gerado durante sua curta existência. Seu escape ocorre na forma de recuo iônico durante o decaimento- $\alpha$ do núcleo pai com conseqüente difusão do átomo neutro através dos poros internos dos grãos minerais e posterior difusão e transporte intergranular na matriz sólida permeável (TANNER, 1964, 1980). Os átomos de radônio migram para a água subterrânea ou para as camadas superiores do solo. O radônio se concentra nas camadas superiores do solo, de onde eventualmente escapam (TANNER, 1964, 1980).

A distribuição irregular do rádio na matriz sólida, que provavelmente é uma conseqüência dos sucessivos recuos- $\alpha$ que o geraram a partir do ${ }^{238} U$, facilita o escape do radônio imediatamente após o seu decaimento (KRISHNASWAMI et al., 1982; SEMKOW, 1990; SEMKOW; PAREK, 1990). No processo de decaimento- $\alpha$, o íon residual produz ao longo da sua trajetória uma intensa ionização que desorganiza localmente a rede cristalina do sólido. Os defeitos induzidos pela radiação tornam a rede cristalina mais suscetível à dissolução quando em contato com água de chuva, de solo ou água subterrânea resultando em uma lixiviação preferencial das diferentes espécies atômicas nele contida (KIGOSHI, 1971; FLEISCHER, 1982, 1988; SUN; SEMKOW, 1997).

Os estudos sobre a emanação, exalação e transporte de radônio mostram que sua a concentração no solo varia com o tempo, e que estas variações estão freqüen- 
temente associadas não só com a natureza física e química do solo e do ambiente, como porosidade e permeabilidade, tamanho e composição do grão, distribuição do rádio, erosão, compactação e formação do horizonte de solo (MEGUMI; MAMURO, 1974; SEMKOW; PAREK, 1990; GREEMAN; ROSE; JESTER, 1990; WASHINGTON; ROSE, 1992; GREEMAN; ROSE, 1996), mas também com os gradientes de pressão e temperatura, vento e umidade (WASHINGTON; ROSE, 1990, 1992; NAZAROFF, 1992; EDSFELDT, 2001). Greeman e Rose (1996) estimaram coeficientes de emanação em solos variando entre 0,15 a 0,25 para o radônio e de 0,10 a 0,20 para o torônio $\left({ }^{220} \mathrm{Rn}\right)$.

A radioatividade natural no ar, altitude entre 0 e $10 \mathrm{~km}$, é devida principalmente à emanação de elementos radioativos gasosos (isótopos de radônio: ${ }^{219} \mathrm{Rn}\left(\mathrm{t}_{1 / 2}=4\right.$ segundos), ${ }^{220} \mathrm{Rn}$ ( $\mathrm{t}_{1 / 2}=55$ segundos) $\mathrm{e}^{222} \mathrm{Rn}\left(\mathrm{t}_{1 / 2}=3,8\right.$ dias $)$ ), principalmente radônio e torônio, e seus produtos de decaimento (MOLINARI; SNODGRASS, 1990; IVANOVICH; HARMON, 1992). Os diferentes tempos de meia-vida dos isótopos de radônio proporcionam uma diferença entre suas concentrações e de seus descendentes na atmosfera, resultando numa maior concentração dos descendentes do ${ }^{222} \mathrm{Rn}$. Consideráveis variações do nível de radioatividade na atmosfera são observados com o tempo, em geral variações de periodicidade sazonal e diurna são regulares abaixo da estratosfera, estas variações regulares estão sujeitas à flutuações aleatórias causadas por muitos fatores (pressão, temperatura, velocidade e direção do vento, precipitação, etc) (JUNGE, 1963; TUREKIAN; NOZAKI; BENNINGER, 1977).

Os produtos de decaimento do ${ }^{222} \mathrm{Rn}$ com meia-vida mais longa são o ${ }^{210} \mathrm{~Pb}$ $\left(t_{1 / 2}=22\right.$ anos $), o{ }^{210} \mathrm{Bi}\left(t_{1 / 2}=5,02\right.$ dias $)$ e o ${ }^{210} \mathrm{Po}\left(t_{1 / 2}=138,3\right.$ dias $)$, onde o ${ }^{210} \mathrm{~Pb}$ é elemento de maior relevância por seu tempo de meia-vida ser maior que dos outros nuclídeos. Assumindo que toda a atividade dos filhos do ${ }^{226} \mathrm{Ra}$ na atmosfera é proveniente do ${ }^{222} \mathrm{Rn}$, a sua produção e remoção devem obedecer o estado estacionário (WARNECK, 2000). Estes filhos radioativos do ${ }^{222}$ Rn são principalmente íons positivos, que podem associar-se com partículas de ar polarizado, água ou aerosóis. Junge (1963) mostrou que cerca de $90 \%$ da radioatividade natural na atmosfera é encontrado 
em aerosóis com raio entre 0,05 e 0,5 $\mu \mathrm{m}$, e com um tamanho médio de 0,1 $\mu \mathrm{m}$.

\subsection{Distribuição do ${ }^{210} \mathrm{~Pb}$ no solo e na atmosfera}

O ${ }^{210} \mathrm{~Pb}$ é um radioisótopo largamente utilizado em estudo ambientais (IVANOVICH; HARMON, 1992). Sua concentração é enriquecida no solo e decresce à medida que a profundidade aumenta, em solos que permaneceram não-perturbados, por um século ou mais. A atividade do ${ }^{210} \mathrm{~Pb}$ pode variar bastante com a profundidade (MOORE; POET, 1976). A concentração do ${ }^{210} \mathrm{~Pb}$ no solo é devido à difusão do gás ${ }^{222} \mathrm{Rn}$, à sua adsorção nas partículas de solo e ao decaimento do ${ }^{222} \mathrm{Rn}$ na atmosfera seguido por processos de precipitação ou deposição dos seus filhos da atmosfera para o solo (MOORE; POET, 1976; TUREKIAN; NOZAKI; BENNINGER, 1977; IMOBODEN; STILLER, 1982).

Descendentes radioativos do ${ }^{222} \mathrm{Rn}$ atmosférico são continuamente retirados da atmosfera por partículas aerosóis, esta remoção mantém o desequilíbrio radioativo entre os filhos do ${ }^{222} \mathrm{Rn}$ na troposfera inferior, e pode ser usado como ferramenta para determinar o tempo de residência destes aerosóis (POET; MOORE; MARTELL, 1972; MOORE; POET; MARTELL, 1973; RANGARAJAN, 1992). Devido à mudança das condições meteorológicas a taxa de remoção da atmosfera varia nas diferentes localidades continentais, oceânicas e a altas altitudes da atmosfera (WARNECK, 2000; JUNGE, 1963). Os dados publicados por Junge (1963), Martell e Moore (1974), Turekian, Nozaki e Benninger (1977) admitem um tempo de residência variando de 4 - 72 dias, porém subdividido em dois grupos com valores médios de 6 e 35 dias. Junge (1963) verificou que os altos valores, 35 dias, são apropriados para o tempo de residência de aerosóis na troposfera, enquanto que os baixos valores, 6 dias, são aplicáveis somente às camadas da atmosfera mais próximas da superfície da Terra. Martell e Moore (1974) descreveram estes altos valores como uma contribuição de aerosóis estratosféricos, enquanto que os baixos valores representam o tempo de re- 
sidência real da troposfera, que é essencialmente independente da altitude.

Assumindo uma distribuição uniforme do rádio com a profundidade $\left(\mathrm{A}_{226} \mathrm{Ra}=4,4\right.$ $\mathrm{dpm} / \mathrm{g}$ ) Moore e Poet (1976) obtiveram um valor de 3,52 dpm/g de ${ }^{210} \mathrm{~Pb}$ de solo, e subtraindo este valor do total existente de ${ }^{210} \mathrm{~Pb}$ nas várias profundidades, verificaram que a principal contribuição do ${ }^{210} \mathrm{~Pb}$ atmosférico localiza-se nos $20 \mathrm{~cm}$ superiores da camada de solo. Nesta profundidade, considerando apenas a contribuição do ${ }^{210} \mathrm{~Pb}$

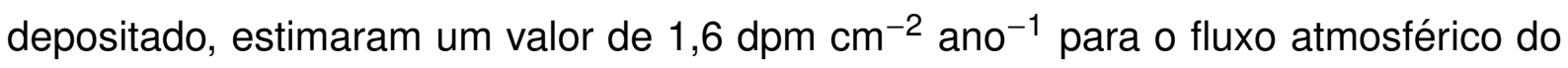
${ }^{210} \mathrm{~Pb}$, valor muito próximo do encontrado por Fisenne (apud MOORE; POET, 1976), 1,2 dpm cm ${ }^{-2}$ ano $^{-1}$, e por Benninger, Lewis e Turekian (apud MOORE; POET, 1976), 0,8 - 1,2 dpm $\mathrm{cm}^{-2}$ ano $^{-1}$, ambos usando uma técnica similar. As altas taxas de precipitação devem encontradas próximas ao Equador, onde o tempo de residência atmosférico pode ser curto e uniforme (POET; MOORE; MARTELL, 1972; MOORE; POET; MARTELL, 1973).

A taxa de precipitação do ${ }^{210} \mathrm{~Pb}$ pode ser determinada diretamente, utilizandose coletores especialmente projetados, ou indiretamente, medindo-se a distribuição do ${ }^{210} \mathrm{~Pb}$ no solo (POET; MOORE; MARTELL, 1972). A distribuição do ${ }^{210} \mathrm{~Pb}$ no solo está associada a movimentação do ${ }^{222} \mathrm{Rn}$, que se conhecida pode ser usada para estimar a atividade do ${ }^{210} \mathrm{~Pb}$ proveniente da atmosfera (IMOBODEN; STILLER, 1982).

\subsection{Ocorrência do potássio em solos}

Em solos formados sobre rocha granítica a taxa de alteração dos minerais que contém o potássio, como o feldspato potássico, e o fluxo de água podem controlar a quantidade de potássio presente nestes solos. Após sua entrada na solução do solo, o $\mathrm{K}^{+}$também é usado na formação de minerais potássicos do solo, adsorvido sobre argila ou removido por migração fluida (HEIER; BILLINGS, 1978). Nos solos o potássio está presente nos fragmentos de minerais potássicos, e algumas vezes apresenta concentrações enriquecidas devido ao comportamento do $\mathrm{K}^{+}$no ciclo biológico, 
e adsorção em lamas e argilas (COCCO; FONFANI; ZANAZZI, 1978). 


\section{Medidas de atividade por espectrometria de raios $-\gamma$}

A atividade do ${ }^{40} \mathrm{~K}$ e dos radionuclídeos pertencentes às séries radioativas do urânio $\left({ }^{238} \mathrm{U}\right)$ e do tório $\left({ }^{232} \mathrm{Th}\right)$ foi determinada por espectrometria gama, seguindo a metodologia descrita por Ribeiro et al. (2001).

A atividade do isótopo ${ }^{226} \mathrm{Ra}$ foi estimada medindo-se a atividade dos seus produtos de decaimento de meia-vida curta, o ${ }^{214} \mathrm{~Pb}$ e o ${ }^{214} \mathrm{Bi}$, em uma condição que, se espera, garanta a existência de equilíbrio radioativo secular entre esses nuclídeos. No caso do ${ }^{214} \mathrm{~Pb}$ foram utilizados os picos de absorção total com 295,4 keV e com $351,0 \mathrm{keV}$ de energia. No caso do ${ }^{214} \mathrm{Bi}$ foram utilizados os picos de absorção total com $609,0 \mathrm{keV}$ e com $1764,0 \mathrm{keV}$ de energia.

A atividade do isótopo ${ }^{238} \mathrm{U}$ foi estimada indiretamente através da atividade do isótopo ${ }^{235} \mathrm{U}$, que inicia a série do actínio, medida utilizando-se a seu pico de absorção total de $185,9 \mathrm{keV}$. A atividade do ${ }^{238} \mathrm{U}$ é estimada assumindo uma razão isotópica constante para o urânio natural de $0,7205 \%$ de núcleos de ${ }^{235} \mathrm{U}$ e de $99,2738 \%$ de núcleos de ${ }^{238} \mathrm{U}$. O pico de absorção total com $185,9 \mathrm{keV}$ do ${ }^{235} \mathrm{U}$ superpõe-se ao pico de absorção total com $186,2 \mathrm{keV}$ do ${ }^{226} \mathrm{Ra}$. O efeito dessa superposição pode ser corrigido quando a atividade do ${ }^{226}$ Ra pode ser estimada com boa precisão a partir das atividades dos seus produtos de decaimento de meia-vida curta (RIBEIRO et al., 2001).

A atividade do ${ }^{210} \mathrm{~Pb}$ foi estimada diretamente através do seu pico de absorção 
total com 46,5 keV de energia.

O isótopo ${ }^{228} \mathrm{Ra}$ não emite radiação- $\gamma$. A sua atividade foi estimada medindose a atividade- $\gamma$ do seu produto de decaimento, o ${ }^{228} \mathrm{Ac}$, utilizando-se os seus picos de absorção total com 911,2 keV e com 968,9 keV de energia. A atividade do ${ }^{228} \mathrm{Th}$ foi estimada medindo-se a atividade do seu descendente de meia-vida curta, o ${ }^{208} \mathrm{TI}$, usando os seus picos de absorção total com 583,2 keV e com 860,6 keV, em uma condição que garanta a existência de equilíbrio radioativo secular entre eles.

A atividade do ${ }^{40} \mathrm{~K}$ foi estimada diretamente através do seu pico de absorção total com 1460,4 keV de energia.

O espectrômetro- $\gamma$ utilizado é munido de um detector coaxial de germânio hiperpuro, com um volume de $253 \mathrm{~cm}^{3}$ e com uma eficiência relativa nominal de $70 \%$. A sua resolução para o pico de absorção total do ${ }^{60} \mathrm{Co}$ com 1332,9 keV é de 2,153, com um desvio padrão de 0,075, determinada a partir de 51 estimativas individuais.

\subsection{Local de coleta das amostras}

As amostras foram coletadas no terreno do Instituto de Botânica da Secretaria de Meio Ambiente do Estado de São Paulo, que está localizado no Parque Estadual das Fontes do Ipiranga, no bairro da Água Funda na cidade de São Paulo.

No final do século XIX, o terreno que hoje corresponde ao Parque Estadual das Fontes do Ipiranga fazia parte de uma extensa área de vegetação nativa, esparçamente ocupada por pequenas propriedades rurais. Em 1893, o governo do Estado de São Paulo, com o objetivo de recuperar a vegetação nativa e proteger os mananciais locais, declarou a área como sendo de utilidade pública e estabeleceu o "Parque do Estado", com uma área aproximada de 6.700.000 metros quadrados. Em 1917, toda a área do Parque passou para a propriedade do Estado. O Jardim Botânico, que hoje faz parte do Instituto de Botânica foi formalmente estabelecido em 1938. 
O local de onde as amostras foram retiradas está localizada em uma área de mata preservada no Jardim Botânico. A cobertura vegetal é densa e não tem sido significantemente perturbada, pelo menos, desde o estabelecimento da instituição. Em conseqüência, as camadas superiores do solo local também não foram diretamente perturbadas desde 1938.

A região do Parque Estadual das Fontes do Ipiranga e, em particular, do Jardim Botânico foi exposta a uma intensa poluição atmosférica associada à atividade industrial nas suas vizinhanças durante a segunda metade do século XX, até a, aproximadamente, dez anos atrás (SECRETARIA DE MEIO AMBIENTE DO ESTADO DE SÃO PAULO, 2006).

\subsection{Coleta e descrição das amostras}

As amostras de solo foram coletadas em um único local em três furos feitos com um trado manual. Os três furos são muito próximos uns dos outros e definem os vértices de um arranjo triangular, figura 3.1, aproximadamente equilátero, com um metro de lado. A profundidade total dos furos é de 2,10 metros. No centro do arranjo, um quarto furo foi feito para retirar amostras destinadas à descrição do solo.

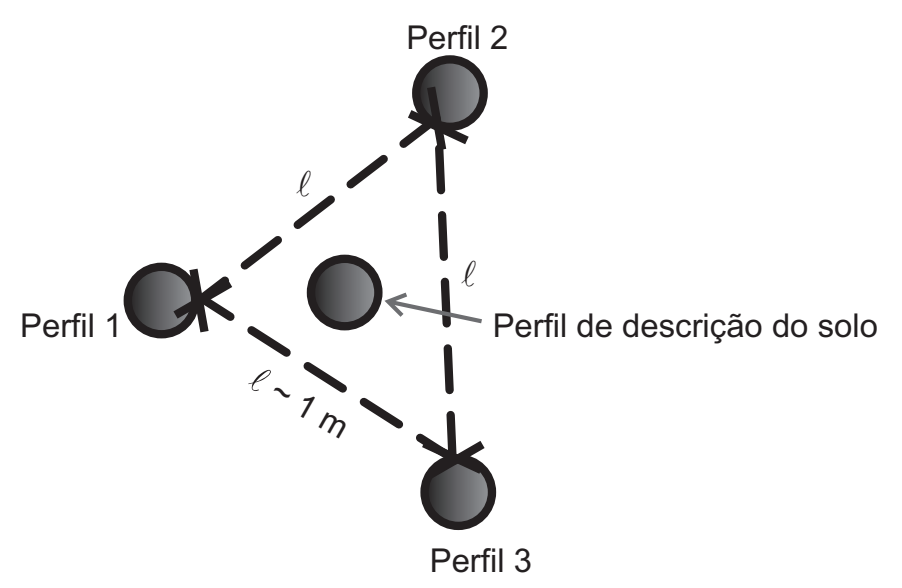

Figura 3.1: Distribuição horizontal dos perfis de amostragem do solo retirado no Instituto de Botânica.

Em cada furo, o material retirado a cada intervalo de profundidade de $0,30 \mathrm{~m}$ 
compôs uma amostra. Foram retiradas, no total, vinte e uma amostras para análise da radioatividade natural e sete amostras para descrição do solo. A massa das amostras variaram entre $1,10 \mathrm{~kg}$ e $1,50 \mathrm{~kg}$.

Todo o intervalo perfurado corresponde à camada de solum. Nenhum dos furos atingiu o nível de saprólito. A tabela 3.1 apresenta a descrição das camadas do solo amostrado. Trata-se de um latossolo desenvolvido sobre uma rocha quartzofeldspática (granitóide). A maior parte do intervalo de profundidades amostrado, entre 0,60 e 2,10 m, corresponde ao horizonte B. Entre 0,30 e 0,60 m observa-se a transição de um horizonte A para um horizonte B. A camada mais superficial de 0,30 m de espessura corresponde aos horizontes $\mathrm{A}$ e $\mathrm{O}$.

Tabela 3.1: Descrição da camada de solo amostrada no terreno do Jardim Botânico de São Paulo, Parque Estadual das Fontes do Ipiranga (baseado na descrição feita pelo Professor Joel B. Sígolo do Instituto de Geociências da USP).

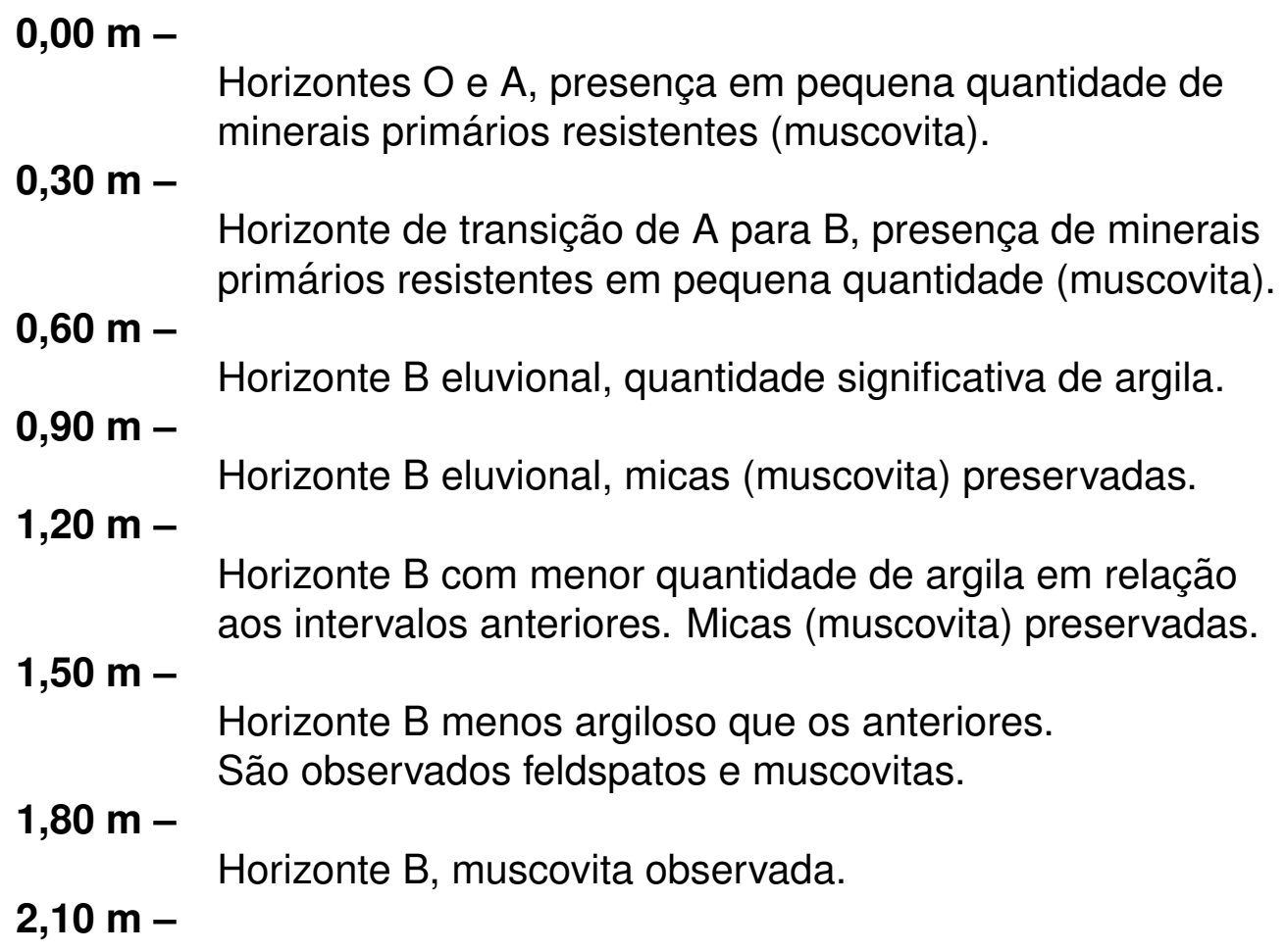




\subsection{Preparação das amostras}

No laboratório, as amostras foram secas em uma estufa a aproximadamente $50^{\circ} \mathrm{C}$ por 72 horas. As amostras já secas foram fragmentadas à mão, quarteadas e uma alíquota com massa de aproximadamente $0,5 \mathrm{Kg}$ foi separada e moída em um moinho de ágata até que nenhum resíduo ficasse retido em uma peneira com uma malha de 60 mesh, escala ABNT, o que corresponde a fragmentos com dimensões inferiores a 0,250 milímetros. O material foi homogeneizado mecanicamente por um período de 2 a 3 horas e hermeticamente encerrado em caixas de poliestireno rígido, com $90 \mathrm{~mm}$ de diâmetro e $46 \mathrm{~mm}$ de altura, de modo a preencher totalmente o seu volume, em seguida pesadas e seladas. As massas das amostras variaram entre, aproximadamente, $370 \mathrm{~g}$ e $445 \mathrm{~g}$ (tabela 3.2).

As amostras permaneceram fechadas por um período mínimo de 45 dias, para o estabelecimento do equilíbrio radioativo secular entre o ${ }^{226} \mathrm{Ra}$ e seus descendentes de meia-vida curta, o ${ }^{214} \mathrm{~Pb}$ e o ${ }^{214} \mathrm{Bi}$, e entre o ${ }^{228} \mathrm{Th}$ e seus descendentes de meia-vida curta, o ${ }^{212} \mathrm{Bi}$ e o ${ }^{208} \mathrm{TI}$.

Tabela 3.2: Massa das amostras de solo utilizadas na determinação das atividades nos intervalos de amostragem dos três perfis.

\begin{tabular}{cccc}
\hline $\begin{array}{c}\text { Profundidade } \\
(\mathbf{m})\end{array}$ & Perfil 1 & Massa (g) \\
\cline { 2 - 4 } & & & Perfil 2 \\
\hline & & & \\
$0,00-0,30$ & $409,292 \pm 0,005$ & $397,375 \pm 0,005$ & $416,675 \pm 0,005$ \\
$0,30-0,60$ & $443,778 \pm 0,005$ & $430,340 \pm 0,005$ & $413,517 \pm 0,005$ \\
$0,60-0,90$ & $382,123 \pm 0,005$ & $402,348 \pm 0,005$ & $402,168 \pm 0,005$ \\
$0,90-1,20$ & $381,235 \pm 0,005$ & $392,720 \pm 0,005$ & $389,795 \pm 0,005$ \\
$1,20-1,50$ & $373,195 \pm 0,005$ & $399,763 \pm 0,005$ & $387,278 \pm 0,005$ \\
$1,50-1,80$ & $370,225 \pm 0,005$ & $380,720 \pm 0,005$ & $391,420 \pm 0,005$ \\
$1,80-2,10$ & $385,435 \pm 0,005$ & $391,187 \pm 0,005$ & $379,901 \pm 0,005$ \\
\hline
\end{tabular}




\subsection{Padrões de atividade}

As atividades dos diversos radionuclídeos contidos nas amostras de solo foram medidas comparando-se as áreas dos picos de absorção total observados com as correspondentes áreas observadas em padrões secundários de radioatividade preparados em laboratório.

Para as medidas de atividade dos radionuclídeos da série do ${ }^{238} \mathrm{U}$ foi utilizado o padrão secundário, LGTSI05, preparado diluindo-se em quartzo moído o padrão CRM-38 (RIBEIRO et al., 2001). Esse padrão, fornecido pelo Laboratório Nacional New Brunswick do Departamento de Energia dos Estados Unidos, é uma pechblenda contendo $3,90 \%$ de $\mathrm{U}_{3} \mathrm{O}_{8}$, onde o ${ }^{238} \mathrm{U}$ está em equilíbrio radioativo secular com o ${ }^{226} \mathrm{Ra}$.

Para as medidas de atividade dos radionuclídeos da série do ${ }^{232}$ Th foi utilizado o padrão secundário, LTGSI06, diluindo-se em quartzo moído o padrão NBL79A, também do Laboratório Nacional New Brunswick. A concentração de tório nesse padrão é de $1 \%$. O material contém também 0,04\% urânio natural.

Os dois padrões estão encerrados em caixas idênticas às utilizadas para armazenar as amostras de solo. A tabela 3.3 lista as características desses dois padrões.

A comparação direta das áreas dos picos de absorção total observados nas amostras, com as áreas dos picos correspondentes observados nos padrões, requer que a amostra e os padrões tenham coeficientes de atenuação da radiação- $\gamma$ muito parecidos, ou iguais.

O coeficiente de atenuação da radiação- $\gamma$ é função tanto da energia da radiação, quanto da densidade e da composição do material. A tabela 3.4 foi construída com dados do coeficiente de atenuação para vários materiais, extraídos de Kogan, Nazarov e Fridman (1971) e de Debertin e Helmer (1988). Os valores apresentados nessa tabela mostram que, com excessão da água, os coeficientes de absorção variam pouco para 
energias superiores a $200 \mathrm{keV}$. Em particular, os coeficientes de atenuação na sílica e no material geológico são bastante semelhantes.

No caso da radiação gama emitida pelo ${ }^{210} \mathrm{~Pb}(46,7 \mathrm{keV})$ a diferença entre os coeficientes de atenuação da sílica e do material geológico é significativa.

Para a determinação da atividade do ${ }^{210} \mathrm{~Pb}$ contido nas amostras de solo foram preparados padrões secundários de atividade do ${ }^{210} \mathrm{~Pb}$ em duas matrizes estéreis com coeficientes de atenuação linear diferente da matriz de solo. Foram escolhidas as matrizes de quartzo moído $\left(\mathrm{SiO}_{2}\right)$ e a matriz de carbonato de cálcio $\left(\mathrm{CaCO}_{3}\right)$ para preparação destes padrões secundários de atividade. O procedimento para se determinar a atividade do ${ }^{210} \mathrm{~Pb}$ nas amostras de solo a partir destes padrões secundários é detalhado no capítulo 4.

A preparação dos padrões secundários primeiramente consistiu em adicionar alíquotas de um padrão líquido secundário de ${ }^{210} \mathrm{~Pb}$ com atividade específica de $(76,59 \pm 0,74) \mathrm{Bq} / \mathrm{g}$ nas matrizes de $\mathrm{CaCO}_{3}$ e de $\mathrm{SiO}_{2}$. Na matriz de $\mathrm{SiO}_{2}$ com massa de $(528,190 \pm 0,007) \mathrm{g}$ foi adicionada uma alíquota de $(1,0293 \pm 0,0001) \mathrm{g}$ do padrão líquido secundário de ${ }^{210} \mathrm{~Pb}$ e na matriz de $\mathrm{CaCO}_{3}$, com uma massa de $(529,955 \pm$ 0,007) g, foi adicionado uma alíquota com $(1,0349 \pm 0,0001) \mathrm{g}$ de massa.

O padrão líquido secundário foi obtido da diluição do padrão 58L97 fornecido pelo Instituto de Radioproteção e Dosimetria da Comissão Nacional de Energia Nuclear. A diluição foi realizada no laboratório do Instituto de Pesquisas Energéticas e Nucleares da CNEN, em São Paulo.

Os conjuntos, em seguida, foram deixados secar espontaneamente e mecânicamente homogeneizados por um período de aproximadamente 3 horas. A maior parte das massas totais dos conjuntos de $\mathrm{CaCO}_{3}$ e $\mathrm{SiO}_{2}$, contendo o ${ }^{210} \mathrm{~Pb}$, foi acondicionada em recipientes de poliestireno rígido. A massa do padrão de ${ }^{210} \mathrm{~Pb}$ em $\mathrm{SiO}_{2}$ é de $(464,355 \pm 0,005) \mathrm{g}$ e a sua atividade total é de $(69,30 \pm 0,67) \mathrm{Bq}$. A massa do padrão de ${ }^{210} \mathrm{~Pb}$ em $\mathrm{CaCO}_{3}$ é de $(440,355 \pm 0,005) \mathrm{g}$ e a sua atividade total é de $(65,86 \pm$ 
0,64) Bq. A tabela 3.3 resume as principais características dos padrões. 


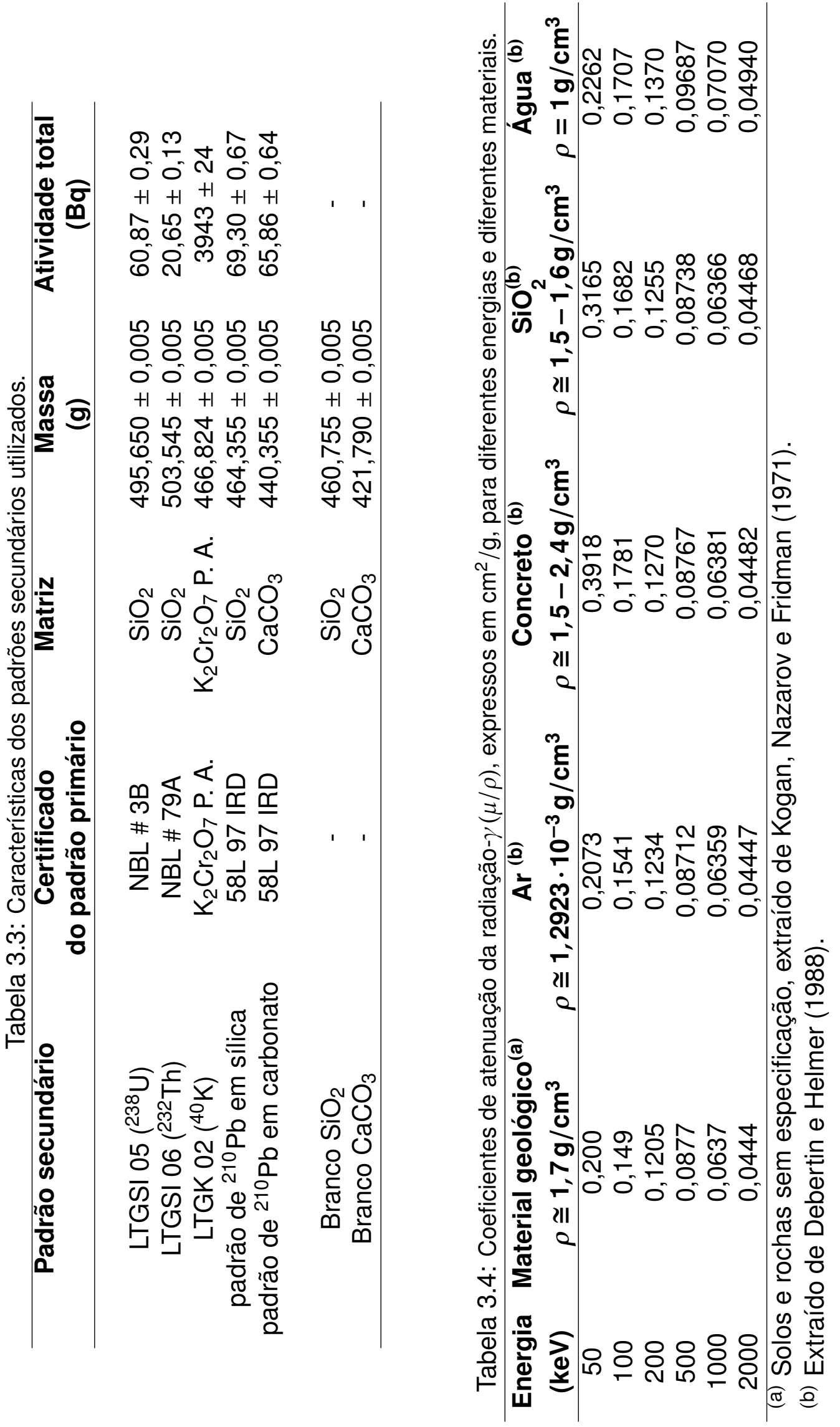




\subsection{Cálculo da atividade de elementos $\gamma$-emissores em amostras ambientais}

A atividade de todos os nuclídeos que emitem radiação- $\gamma$ com uma energia característica pode ser relacionada com a área do pico de absorção total, formado nessa energia, por (DEBERTIN; HELMER, 1988):

$$
P=\sum_{k=1}^{n} \cdot A_{k} \cdot p_{k}(E) \cdot \varepsilon(E) \cdot e^{-\lambda_{k} t} \cdot T
$$

onde $\mathrm{P}$ é a área do pico de absorção total, $\mathrm{A}_{\mathrm{k}}$ é a atividade do k-ésimo nuclídeo que contribui para a formação do pico de absorção total, $p_{k}(E)$ é a probabilidade de emissão de um fóton com energia $E$ pelo $k$-ésimo nuclídeo, $\varepsilon(E)$ é a eficiência absoluta de detecção dependente da energia do fóton da atenuação da radiação- $\gamma$ na matriz da amostra e da geometria de detecção, $\lambda_{\mathrm{k}}$ é a constante de decaimento do k-ésimo nuclídeo que contribui para a formação do pico de absorção total, $t$ o tempo de decaimento da amostra e T é o tempo de duração da contagem.

Caso o pico de absorção total seja formado pelo decaimento de um único nuclídeo e o tempo de decaimento da amostra, $t$, seja muito menor que o seu tempo de meia-vida a soma das contribuições de todos os nuclídeos, equação 3.1, reduz-se a contribuição de apenas um isótopo, $k=1$, que relaciona sua atividade com o seu respectivo pico de absorção total e tempo de contagem,

$$
P=A \cdot p(E) \cdot \varepsilon(E) \cdot T
$$

As medidas $\gamma$-espectrométricas de uma série radioativa natural nem sempre pode ser aplicada a todos os radionuclídeos dessas séries cujas atividades sejam desejadas, por não emitirem um fóton durante seu decaimento. Nesse caso, a atividade destes nuclídeos pode ser obtida através de um, ou mais, produtos de seu decaimento, desde que o produto de decaimento seja um emissor- $\gamma$ com energia mensurável e a 
situação de equilíbrio radioativo secular entre os radionuclídeos, pai e filho tenha sido alcançado, através da equação 3.2, que permanece válida se a geometria de detecção e a atenuação da radiação- $\gamma$ na amostra e no padrão forem as mesmas.

Conhecida a atividade do padrão secundário e as áreas de seus picos de absorção total, correspondentes a um nuclídeo em particular com uma energia de emissão $\mathrm{E}$, a atividade deste pode ser estimada através da relação 3.2 modificada para acomodar a área do pico de absorção, a atividade do padrão e da amostra, e seus respectivos tempos de contagem:

$$
\frac{P_{a}}{P_{p}}=\frac{A_{a} \cdot T_{a}}{A_{p} \cdot T_{p}}
$$

onde os índices a e p referem-se à amostra e ao padrão, respectivamente.

Um radionuclídeo que possua várias linhas de emissão- $\gamma$ com energias diferentes, como, por exemplo, o ${ }^{214} \mathrm{~Pb}$, permite a obtenção de um conjunto de estimativas independentes da sua atividade. Admitindo, em primeira aproximação, que cada uma dessas estimativas podem ser consideradas como um valor extraído de uma distribuição normal, a estimativa de maior probabilidade para a atividade desse radionuclídeo é dada pela média $(\bar{x})$ dos valores individuais $\left(x_{i}\right)$ ponderada pelo inverso dessas variâncias $\left(\sigma_{\mathrm{i}}\right)$ :

$$
\bar{x}=\frac{\sum_{i=1}^{n}\left(\frac{x_{i}}{\sigma_{i}^{2}}\right)}{\sum_{i=1}^{n}\left(\frac{1}{\sigma_{i}^{2}}\right)}
$$

o desvio padrão associado a essa estimativa é dado por (VUOLO, 1996):

$$
\sigma^{2}=\frac{1}{\sum_{i=1}^{n} \frac{1}{\sigma_{i}^{2}}}
$$


Para se verificar se o valor médio fornecido pela equação 3.4 é representativo dos valores individuais, aplica-se o teste do $\chi^{2}$ tal como descrito, por exemplo, em Vuolo (1996). Nesse caso, o valor observado da variável qui-quadrado $\left(\chi_{\mathrm{obs}}^{2}\right)$ é dado por:

$$
\chi_{\mathrm{obs}}^{2}=\sum_{\mathrm{i}=1}^{\mathrm{n}}\left(\frac{\mathrm{x}_{\mathrm{i}}-\overline{\mathrm{x}}}{\sigma_{\mathrm{i}}}\right)^{2}
$$

Em todas as aplicações do teste $\chi^{2}$ adotou-se o valor de 0,05 para o nível de significância $(\alpha)$.

O mesmo critério pode ser adotado para se estimar a atividade de um radionuclídeo, como, por exemplo, o ${ }^{226} \mathrm{Ra}$, medindo-se as atividades de seus produtos de decaimento, neste caso o ${ }^{214} \mathrm{~Pb}$ e o ${ }^{214} \mathrm{Bi}$. Nesse caso, no entanto, é necessário que os radionuclídeos estejam em equilíbrio radioativo secular.

$A$ atividade do ${ }^{238} \mathrm{U}$ na amostra, $\mathrm{A}\left({ }^{238} \mathrm{U}\right)_{\mathrm{a}}$, foi calculada através da relação (RIBEIRO et al., 2001):

$$
A\left({ }^{238} U\right)_{a}=(2,332 \pm 0,026) \cdot \frac{P_{a} T_{p}}{P_{p} T_{a}} \cdot A\left({ }^{226} R a\right)_{p}-(1,332 \pm 0,026) \cdot A\left({ }^{226} R a\right)_{a}
$$

onde $A\left({ }^{226} \mathrm{Ra}\right)_{a}$ e $A\left({ }^{226} \mathrm{Ra}\right)_{p}, T_{a}$ e $T_{p}$ são, respectivamente, as áreas do pico de absorção total formado pela superposição dos decaimentos do ${ }^{235} \mathrm{U}(185,7 \mathrm{keV})$ e do ${ }^{226} \mathrm{Ra}$ e os respectivos tempos de aquisição dos espectros das amostras e dos padrões.

\subsection{Radiação de fundo, níveis críticos e limites de de- tecção qualitativa}

A tabela 3.5 apresenta as áreas dos diversos picos de absorção total dos radionuclídeos, escolhidos para a determinação das concentrações de potássio, urânio e 
tório, e obtidos durante a observação da radiação de fundo feita com o padrão estéril de quartzo moído $\left(\mathrm{SiO}_{2}\right)$. A tabela 3.5 apresenta também os níveis críticos $\left(\mathrm{N}_{\mathrm{C}}\right)$ e os limites de detecção qualitativa $\left(L_{D}\right)$, tais como definidos por Currie (1968), assumindose erros máximos do tipo I e do tipo II (para $N_{C}$ e $L_{D}$, respectivamente) de 0,05.

Tabela 3.5: Contagem da radiação de fundo observada em um período de 48 horas com o padrão estéril LTGSI05 (quartzo moído), níveis críticos e limites de detecção qualitativa correspondentes aos diversos radionuclídeos utilizados.

\begin{tabular}{ccccc}
\hline Nuclídeo & $\begin{array}{c}\text { Energia } \\
\text { (keV) }\end{array}$ & $\begin{array}{c}\text { Contagem } \\
\text { de fundo* }\end{array}$ & $\begin{array}{c}\text { Nível crítico } \\
\left(\mathbf{N}_{\mathbf{C}}\right)^{*}\end{array}$ & $\begin{array}{c}\text { Limite de } \\
\text { detecção }\left(\mathbf{L}_{\mathbf{D}}\right)^{*}\end{array}$ \\
\hline${ }^{214} \mathrm{~Pb}$ & 295,1 & $2384 \pm 79$ & 183 & 369 \\
& 351,9 & $4071 \pm 93$ & 216 & 435 \\
${ }^{214} \mathrm{Bi}$ & 609,3 & $3119 \pm 75$ & 174 & 351 \\
& 1764,5 & $846 \pm 39$ & 114 & 185 \\
& & & & \\
${ }^{228} \mathrm{AC}$ & 911,2 & $2123 \pm 62$ & 144 & 291 \\
& 969 & $1210 \pm 87$ & 202 & 407 \\
${ }^{208} \mathrm{TI}$ & 583 & $2866 \pm 77$ & 179 & 361 \\
& 860,6 & $355 \pm 43$ & 100 & 203 \\
${ }^{40} \mathrm{~K}$ & 1460,8 & $12443 \pm 121$ & 281 & 565 \\
\hline${ }^{*}$ número de contagens por um período de 48 horas.
\end{tabular}

A tabela 3.6 apresenta as áreas do pico de absorção total do ${ }^{210} \mathrm{~Pb}$ com $46,5 \mathrm{keV}$ observados nos padrões estéreis de quartzo moído (LTGSIPb) de carbonato de cálcio (LGTCARPb). A tabela apresenta também os níveis críticos e os limites de detecção qualitativa para cada um dos padrões secundários.

Tabela 3.6: Contagem da radiação de fundo, em um período de 48 horas, na região do pico de absorção total do ${ }^{210} \mathrm{~Pb}$ com $46,5 \mathrm{keV}$ de energia, nível crítico e limite de detecção qualitativa nos padrões LGTSIPb e LGTCARPb.

\begin{tabular}{ccccc}
\hline $\begin{array}{c}\text { Padrão } \\
\text { estéril }\end{array}$ & Matriz & $\begin{array}{c}\text { Contagem } \\
\text { de fundo* }\end{array}$ & $\begin{array}{c}\text { Nível crítico } \\
\left(\mathbf{N}_{\mathbf{C}}\right)^{*}\end{array}$ & $\begin{array}{c}\text { Limite de } \\
\text { detecção }\left(\mathbf{L}_{\mathbf{D}}\right)^{*}\end{array}$ \\
\hline LGTSIPb & $\mathrm{SiO}_{2}$ & $1034 \pm 77$ & 179 & 361 \\
LGTCARPb & $\mathrm{CaCO}_{3}$ & $1018 \pm 84$ & 179 & 395 \\
\hline * número de contagens por um período de 48 horas.
\end{tabular}




\section{O problema da correção do efeito de auto-absorção da radiação- $\gamma$ emitida pelo ${ }^{210} \mathrm{~Pb}$}

A medida da atividade do ${ }^{210} \mathrm{~Pb}$ por espectrometria- $\gamma$, através da sua linha de emissão com 46,5 keV, exige que se aplique uma correção para compensar o efeito da absorção, pela matriz da amostra, da radiação emitida pelo ${ }^{210} \mathrm{~Pb}$ disperso nessa matriz. Existe, na literatura, um número considerável de trabalhos que tratam desse problema de auto-absorção.

Inicialmente Cutshall, Larse e Olsen (1983) elaboraram um técnica experimental para corrigir a auto-absorção do ${ }^{210} \mathrm{~Pb}$ medindo-se a transmissão direta da radiação- $\gamma$ de baixa energia em cada amostra. Para aplicar este método torna-se necessário medir a atividade duas vezes: uma com uma fonte muito ativa de ${ }^{210} \mathrm{~Pb}$ na presença da amostra e uma outra medida na ausência da amostra, onde o coeficiente de correção da auto-absorção proposto por Cutshall, Larse e Olsen (1983) seria a razão entre a atividade da amostra medida com a fonte de ${ }^{210} \mathrm{~Pb}$ sobre ela e a medida correspondente à atividade da fonte de ${ }^{210} \mathrm{~Pb}$ localizada na mesma posição da medida anterior. Baseando-se no trabalho de Cutshall, Larse e Olsen (1983) muitos autores, como Galloway (1991), Appleby, Richardson e Nolan (1992), Bolivar, Garcia-Tenorio e GarciaLeon (1996), Hussain et al. (1996), Miguel et al. (2002), Vargas et al. (2002), trataram do problema da auto-absorção da radiação gama em amostras ambientais para diversas energia e diferentes geometrias, usando diferentes aproximações teóricas e experimentais. 
A seguir é apresentado o método, que foi utilizado neste trabalho, para corrigir o efeito da auto-absorção da radiação- $\gamma$ emitida pelo ${ }^{210} \mathrm{~Pb}$. O método, que é baseado no trabalho original de Cutshall, Larse e Olsen (1983), leva em consideração as geometrias de detecção utilizados, tanto nas medidas do coeficiente de atenuação linear, quanto nas medidas de atividade das amostras e dos padrões.

\subsection{Método de correção da auto-absorção na determi- nação da atividade do ${ }^{210} \mathrm{~Pb}$}

\subsubsection{A determinação do coeficiente de atenuação linear}

A figura 4.1 apresenta um esquema do arranjo experimental utilizado para a medida do coeficiente de atenuação linear das amostras de solo e dos padrões de radioatividade.

A amostra, ou o padrão, encerrada na caixa de poliestireno rígido, é posta sobre o detector de forma que o seu eixo coincida com o eixo do cristal de germânio. A distância entre a amostra e o detector, incluindo as espessuras dos diferentes invólucros é $e_{2}$. Sobre a amostra, é posta uma fonte de radiação- $\gamma$ com forma de uma ampola de vidro parcialmente preenchida por uma solução que contém ${ }^{210} \mathrm{~Pb}$. $\mathrm{O}$ eixo da ampola é feito coincidir com os eixos da amostra e do detector. O raio interno da ampola é a, a altura da solução dentro da ampola é $h$ e a distância da solução à amostra, incluindo as espessuras dos diferentes invólucros, é e $e_{1}$.

Uma vez que o raio da caixa porta-amostra $(B)$ é maior do que o raio do cristal de germânio $(A)$, a radiação primária, emitida pela fonte e que atinge o detector sem ser absorvida ou espalhada, atravessa, com trajetórias com diferentes inclinações, toda a espessura $(E)$ da amostra.

Considerando que a fonte de ${ }^{210} \mathrm{~Pb}$ tenha uma atividade total $\mathrm{C}_{0}$, o fluxo de radiação primária que atinge a superfície do detector é dada por: 


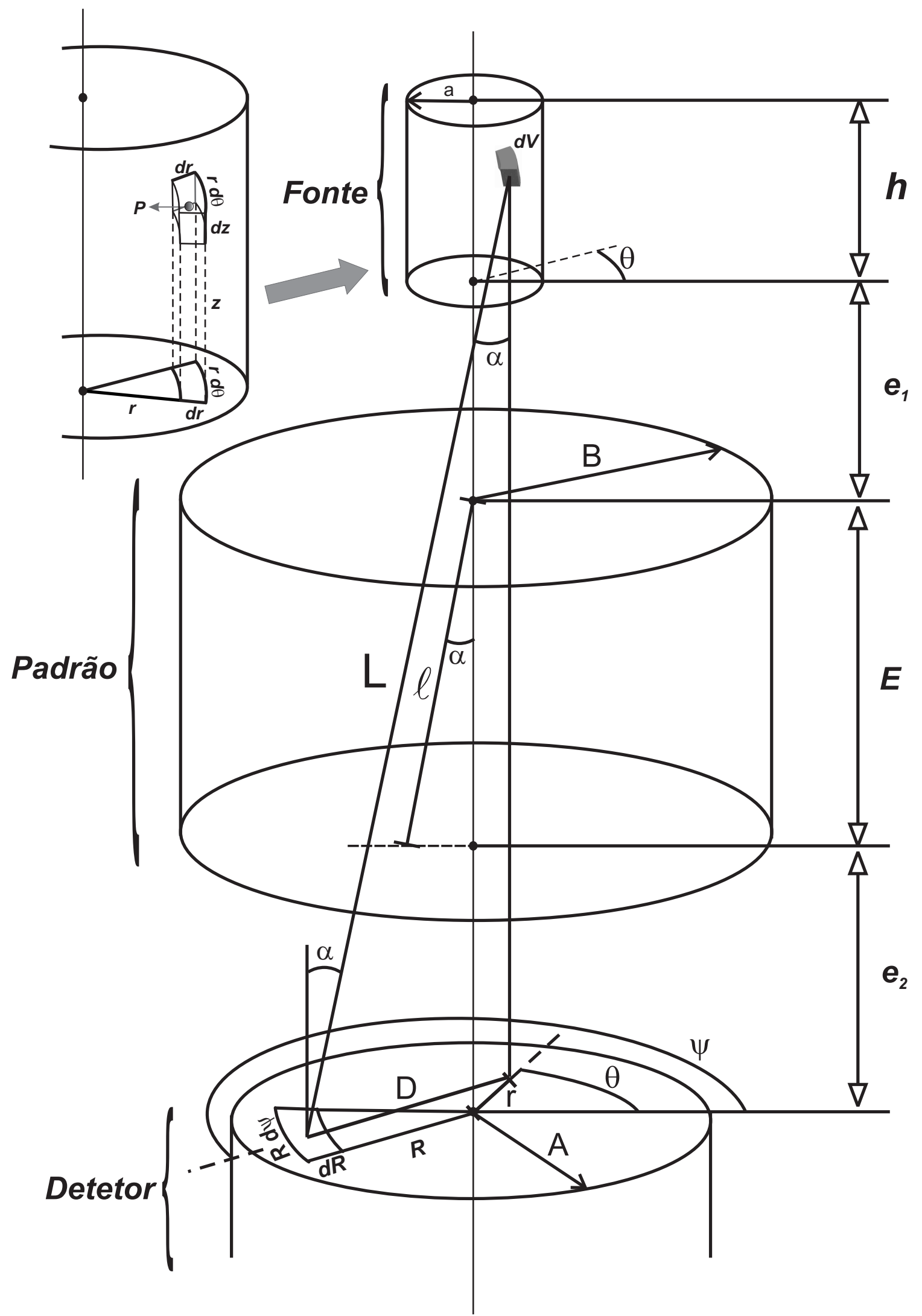

Figura 4.1: Geometria para o ângulo sólido de um fóton incidente sobre a superfície do detector quando emitido por um padrão radioativo secundário localizado sobre a amostra de solo 


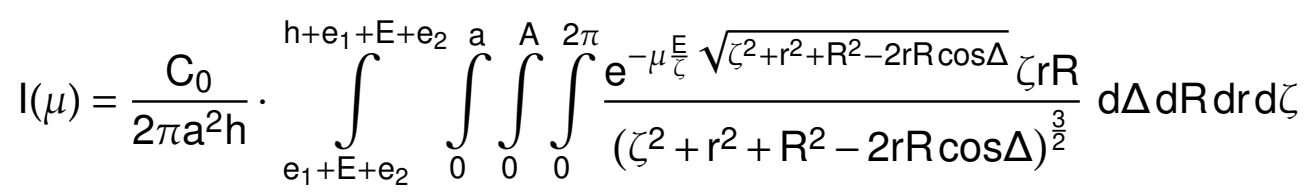

onde $\mu$ é o coeficiente de atenuação linear da radiação- $\gamma$ na amostra. Se o seu diâmetro for pequeno, quando comparado com as outras dimensões do arranjo, a fonte de radiação- $\gamma$ pode ser representada por uma fonte linear de altura $h$. Neste caso, o fluxo de radiação primária que atinge a superfície do detector é

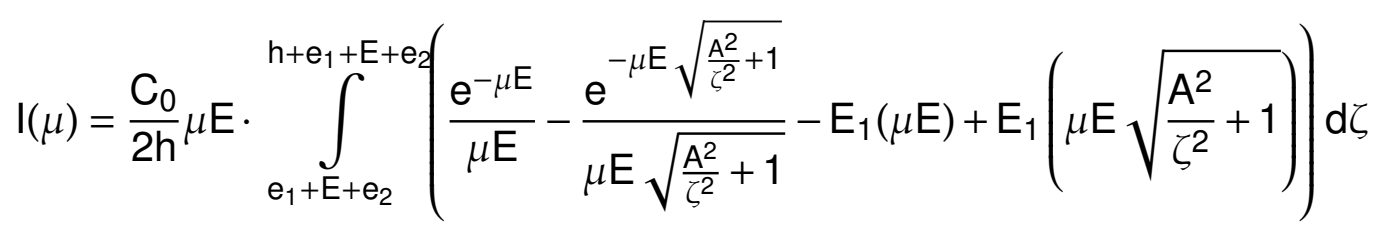

onde,

$$
E_{1}=\int_{x}^{\infty} \frac{e^{-t}}{t^{2}} d t
$$

No apêndice A.2.1 são apresentadas fórmulas para o cálculo da função $E_{1}(x)$ com pequenos erros de aproximação.

Com base na equação 4.2, construiu-se uma extensa tabela dos valores calculados da razão entre a radiação transmitida através da amostra $(\mathrm{T})$ e da radiação incidente sobre a amostra (I), para diferentes valores de $\mu$, dada por

$$
\left(\frac{\mathrm{T}}{\mathrm{T}}\right)_{\text {calculado }}=\frac{\mathrm{I}(\mu)}{\mathrm{I}(\mu=0)}
$$

A figura 4.2 apresenta a variação de $\left(\frac{T}{T}\right)_{\text {calculado }}$ como função do coeficiente de atenuação linear.

Para se ter uma idéia da qualidade da aproximação representada pelo modelo 
de fonte linear, um conjunto menor de valores de $\left(\frac{T}{T}\right)_{\text {calculado }}$ foi calculado pelo modelo de fonte extensa (equação 4.1). A tabela 4.1 compara os resultados obtidos pelos dois modelos até a quarta casa decimal. As integrais contidas nas equações 4.1 e 4.2 foram calculadas usando o método de integração de Gauss-Legendre (PRESS et al., 1986)(apêndice A).

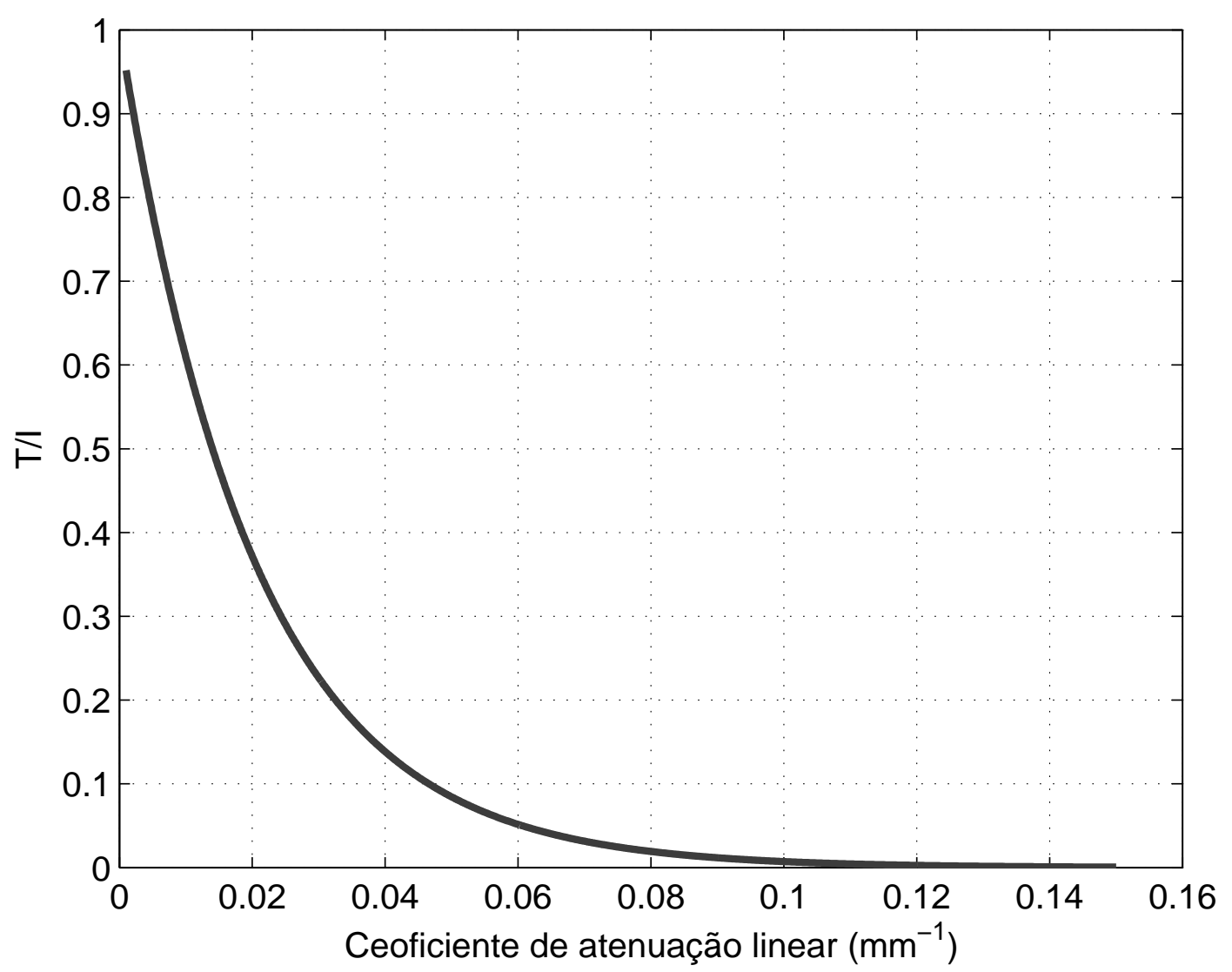

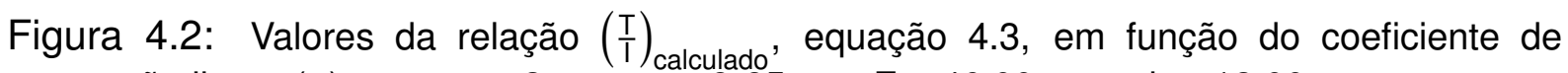
atenuação linear $(\mu)$, com $e_{1}=3 \mathrm{~mm}, e_{2}=8,85 \mathrm{~mm}, E=46,00 \mathrm{~mm}$ e $\mathrm{h}=12,00 \mathrm{~mm}$.

O procedimento para a determinação do coeficiente de atenuação linear consistiu em acumular, por um período de duas horas, o espectro da fonte de ${ }^{210} \mathrm{~Pb}$ utilizando o arranjo experimental esquematizado na figura 4.1. Após o período de contagem calcula-se a área do pico de absorção total correspondente à energia do decaimento do ${ }^{210} \mathrm{~Pb}\left(\mathrm{P}_{1}\right)$. O processo é então repetido substituindo a amostra por uma caixa 
Tabela 4.1: Comparação entre os valores de $\frac{T}{T}$ obtidos através da equação 4.1 (fonte extensa) e através da equação 4.2 (fonte linear). Os parâmetros da fonte extensa são: a =7,90 mm, $A$ $=37,50 \mathrm{~mm}, \mathrm{E}=46,00 \mathrm{~mm}, \mathrm{~h}=12,00 \mathrm{~mm}, \mathrm{e}_{1}=3,00 \mathrm{~mm}$ e $e_{2}=8,85 \mathrm{~mm}$.

\begin{tabular}{ccc}
\hline $\begin{array}{c}\text { Coeficiente de } \\
\text { atenuação linear }\left(\mu, \mathbf{~ e m ~ m}^{-1} \text { ) }\right.\end{array}$ & $\begin{array}{c}\text { T/I } \\
\text { (Fonte linear) }\end{array}$ & $\begin{array}{c}\text { T/I } \\
\text { (Fonte extensa) }\end{array}$ \\
\hline 0,0635 & 0,0434 & 0,0432 \\
0,0614 & 0,0482 & 0,0480 \\
0,0598 & 0,0521 & 0,0519 \\
0,0578 & 0,0575 & 0,0573 \\
0,0557 & 0,0638 & 0,0635 \\
0,0522 & 0,0758 & 0,0755 \\
0,0485 & 0,0910 & 0,0906 \\
0,0454 & 0,1060 & 0,1056 \\
\hline
\end{tabular}

porta-amostras vazia e obtém-se uma área do pico de absorção total $\left(\mathrm{P}_{2}\right)$. Em seguida, acumula-se, também por duas horas, o espectro- $\gamma$ da amostra e o espectro- $\gamma$ da caixa vazia, obtendo-se as áreas do pico de absorção total $\mathrm{P}_{3}$ e $\mathrm{P}_{4}$, respectivamente.

O valor medido da razão $\frac{T}{T}$ é dado por

$$
\left(\frac{T}{\mathrm{~T}}\right)_{\text {medido }}=\frac{\mathrm{P}_{1}-\mathrm{P}_{3}}{\mathrm{P}_{2}-\mathrm{P}_{4}}
$$

e a incerteza desse valor é obtida propagando-se as incertezas dos valores de $P_{1}, P_{2}, P_{3}$ e $P_{4}$. Com base no valor dado pela equação 4.4 , interpola-se, na tabela que deu origem a figura 4.2, o valor de $\mu$ da amostra analisada. A incerteza do valor do coeficiente de atenuação linear é obtida adicionando-se e subtraindo-se do valor médio de $\left(\frac{\mathrm{T}}{\mathrm{T}}\right)_{\text {medido }}$ a sua incerteza e interpolando-se os valores de $\mu$ correspondentes.

\subsubsection{A correção do efeito de auto-absorção pela matriz da amostra}

A fração dos decaimentos sofridos pelo ${ }^{210} \mathrm{~Pb}$ contido na amostra, ou no padrão, com atividade total $\mathrm{C}_{0}$ e que atinge a superfície do cristal de germânio do detector na forma de radiação primária $(\mathrm{I}(\mu))$, pode ser calculado por (ver apêndice $\mathrm{B}$ ) 


$$
\mathrm{G}(\mu)=\frac{\mathrm{I}(\mu)}{\mathrm{C}_{0}} \frac{1}{2 \pi \mathrm{B}^{2} \mathrm{E}} \int_{0}^{\mathrm{E}} \int_{0}^{\mathrm{B}} \int_{0}^{\mathrm{A}} \int_{0}^{2 \pi} \frac{\mathrm{e}^{-\mu \frac{\mathrm{E}}{\mathrm{z}+\mathrm{e}_{2}} \sqrt{\left(\mathrm{z}+\mathrm{e}_{2}\right)^{2}+\mathrm{r}^{2}+\mathrm{R}^{2}-2 \mathrm{rR} \cos \Delta}}\left(\mathrm{z}+\mathrm{e}_{2}\right) \mathrm{rR}}{\left(\left(\mathrm{z}+\mathrm{e}_{2}\right)^{2}+\mathrm{r}^{2}+\mathrm{R}^{2}-2 \mathrm{rR} \cos \Delta\right)^{\frac{3}{2}}} \mathrm{~d} \Delta \mathrm{dR} d \mathrm{rdz}
$$

onde $A$ e $B$ são respectivamente, o raio do cristal de germânio e o raio interno da caixa porta-amostra, $E$ é a espessura da amostra, $e_{2}$ é a distância da amostra ao cristal incluindo a espessura dos diferentes invólucros e $\mu$ é o coeficiente de atenuação linear da amostra para a radiação- $\gamma$ com 46,5 keV de energia.

O fator $\mathrm{G}(\mu)$ dado pela equação 4.5 representa, de forma conjunta, a geometria de detecção e o efeito de auto-absorção na matriz da amostra e corresponde ao fator G descrito na equação 4.6 .

Usando a equação 4.5 uma tabela extensa de valores de $G$ foi calculada para diferentes valores de $\mu$. A figura 4.3 representa a variação de $\mathrm{G}(\mu)$ como função do coeficiente de atenuação linear.

Uma vez obtido o valor de $\mu$ para uma amostra, interpola-se, na tabela que deu origem à figura 4.3, o valor de $\mathrm{G}(\mu)$ da amostra analisada. A incerteza do valor de $\mathrm{G}(\mu)$ é obtida seguindo o mesmo procedimento adotado para se estimar a incerteza do coeficiente de atenuação linear.

O valor da atividade total do ${ }^{210} \mathrm{~Pb}$ contido na amostra $\left(A_{a}\right)$ é obtido por comparação com um padrão de radioatividade com atividade total conhecida $\left(A_{p}\right)$. Nesse caso, modifica-se a equação 3.3 para incluir os fatores $G_{a}$ e $G_{p}$, da amostra e do padrão, respectivamente, na forma

$$
\frac{P_{a}}{P_{p}}=\frac{A_{a} \cdot G_{a} \cdot \Delta t_{a}}{A_{p} \cdot G_{p} \cdot \Delta t_{p}}
$$

onde $\mathrm{P}_{\mathrm{a}}$ e $\mathrm{P}_{\mathrm{a}}$ são as áreas líquidas do pico de absorção total com 46,5 keV 


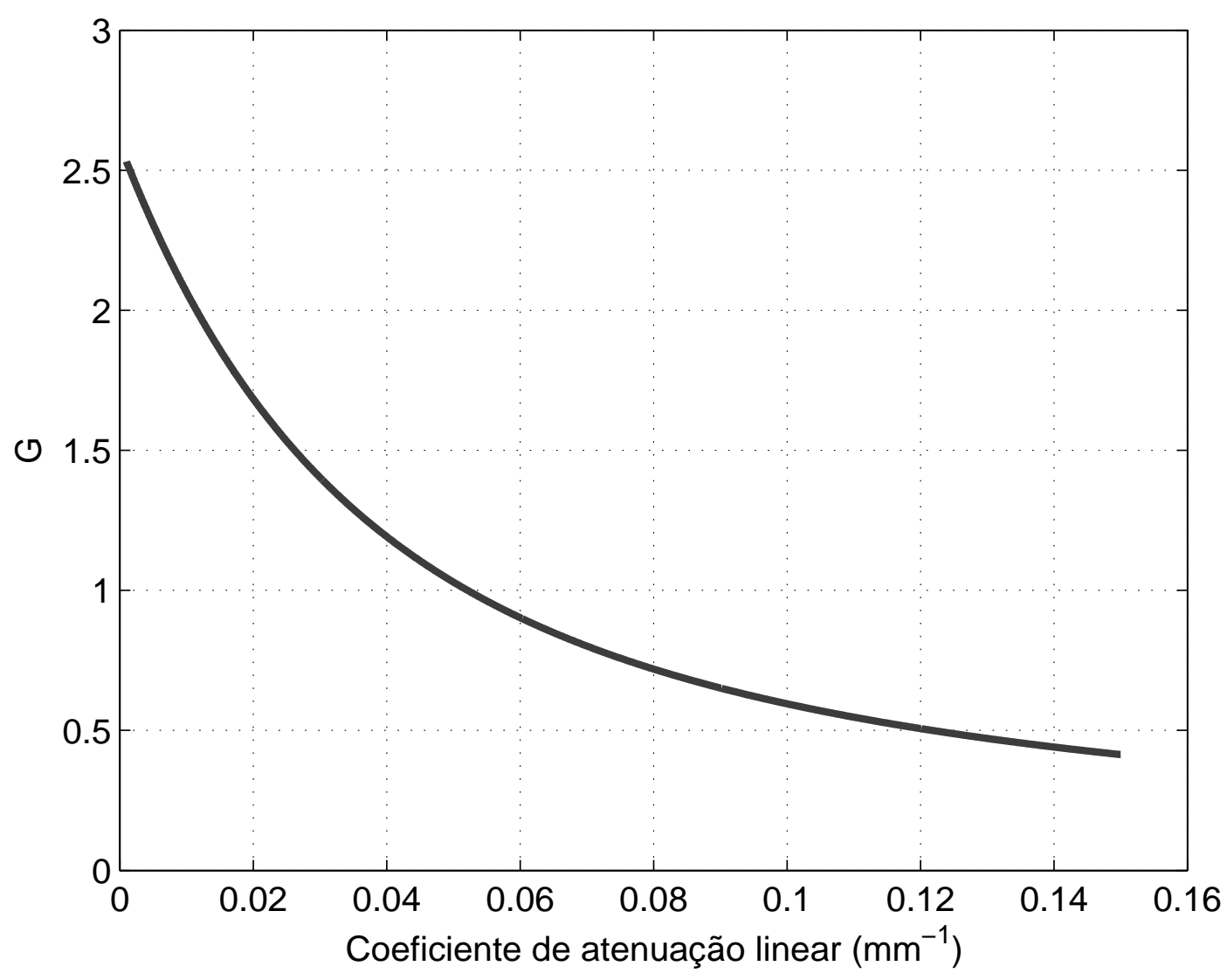

Figura 4.3: Valores do fator de correção da radiação- $\gamma(G)$, equação 4.5, em função do coeficiente de atenuação linear $(\mu), \operatorname{com~} A=37,50 \mathrm{~mm}, B=45,00 \mathrm{~mm}$ e $E=46,00 \mathrm{~mm}$.

do ${ }^{210} \mathrm{~Pb}$, obtidas com tempos de integração $\Delta \mathrm{t}_{\mathrm{a}}$ e $\Delta \mathrm{t}_{\mathrm{p}}$ do espectro da amostra e do padrão, respectivamente.

A tabela 4.2 apresenta os valores do coeficiente de atenuação linear $(\mu)$, em $\mathrm{mm}^{-1}$, a razão entre o coeficiente de atenuação linear e a massa $\left(\frac{\mu}{\mathrm{m}}\right)$, em $(\mathrm{g} \cdot \mathrm{mm})^{-1}, \mathrm{e}$ o fator adimensional para correção do efeito de auto absorção G para as 21 amostras de solo.

Os coeficientes de atenuação variaram entre $(0,0481 \pm 0,0006) \mathrm{mm}^{-1}$ e $(0,0569 \pm$ $0,0008) \mathrm{mm}^{-1}$, enquanto que a razão $\frac{\mu}{\mathrm{m}}$ apresentou um valor médio de $1,32 \cdot 10^{-4}(\mathrm{~g}$. $\mathrm{mm})^{-1}$ com um desvio padrão de $0,08 \cdot 10^{-4}$. A aplicação do teste do $\chi^{2}$ de Pearson, com um nível de significância de 0,05 , mostra que o conjunto de valores são extraídos de uma distribuição normal, o que sugere que a matriz do solo amostrado seja homogênea do ponto de vista da atenuação da radiação- $\gamma$ emitida pelo ${ }^{210} \mathrm{~Pb}$. 
Os coeficientes de atenuação linear dos padrões de atividade com matriz estéril de quartzo moído $\left(\mathrm{SiO}_{2}\right)$ de carbonato de cálcio $\left(\mathrm{CaCO}_{3}\right)$ foram obtidas através de

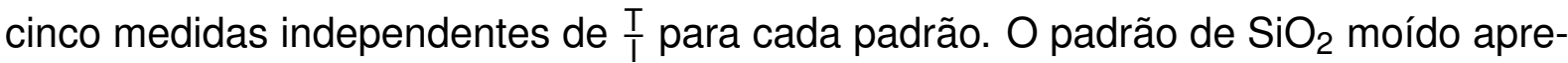
sentou um valor de $\mu$ de $0,0497 \pm 0,0007 \mathrm{~mm}^{-1}$, enquanto que, para o padrão de $\mathrm{CaCO}_{3}$, o valor obtido de $\mu$ foi de $0,0607 \pm 0,0008 \mathrm{~mm}^{-1}$. Os valores obtidos de $\mathrm{G}(\mu)$ foram de $(1,0345 \pm 0,0110)$ e de $(0,8950 \pm 0,0094)$ para os padrões de quartzo moído e de carbonato de cálcio, respectivamente. 


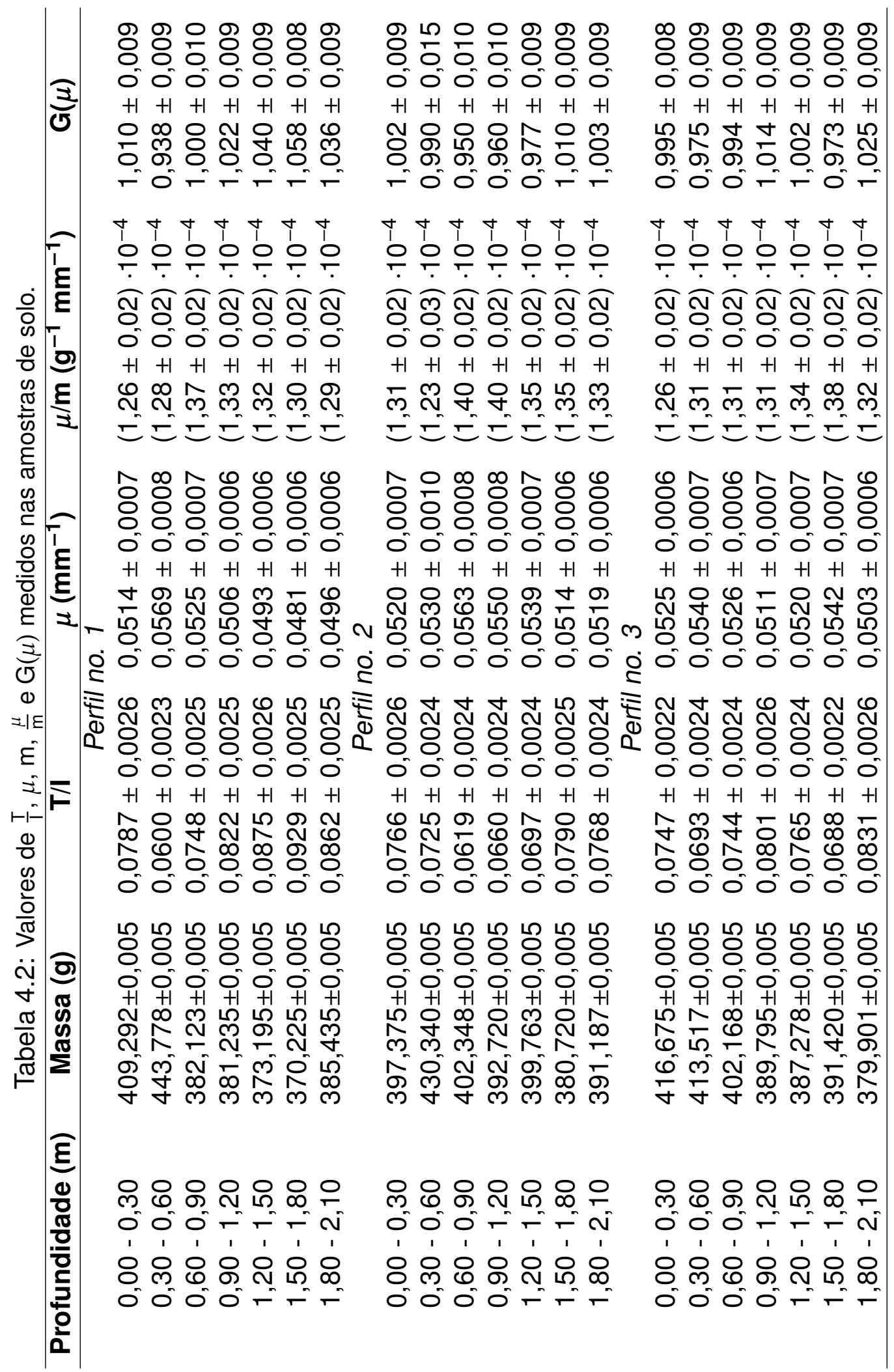




\subsubsection{Uma estimativa da exatidão do método de correção do efeito de auto-absorção}

Uma forma de se verificar a exatidão da correção do efeito de auto-absorção é confrontar a razão das taxas de contagem medidas em dois padrões de radioatividade com diferentes coeficientes de atenuação, como no caso dos padrões de quartzo moído $\left(\mathrm{SiO}_{2}\right)$ e de carbonato de cálcio $\left(\mathrm{CaCO}_{3}\right)$.

$$
\mathrm{R}_{\text {medido }}=\frac{\frac{\mathrm{P}_{\mathrm{SiO}_{2}}}{\Delta \mathrm{t}_{\mathrm{SiO}_{2}}}}{\frac{\mathrm{P}_{\mathrm{CaCO}_{3}}}{\Delta \mathrm{t}_{\mathrm{CaCO}_{3}}}}
$$

com a razão entre as taxas de contagem calculadas utilizando as atividades totais e os fatores de correção

$$
R_{\text {calculado }}=\frac{A_{\mathrm{SiO}_{2}} \cdot \mathrm{G}_{\mathrm{SiO}_{2}}}{\mathrm{~A}_{\mathrm{CaCO}_{3}} \cdot \mathrm{G}_{\mathrm{CaCO}_{3}}}
$$

Se a correção proposta para o efeito de auto-absorção tiver uma boa exatidão, o que se espera é que $R_{\text {medido }}$ e $R_{\text {calculado }}$ coincidam dentro das incertezas de cada estimativa.

Substituindo os valores correspondentes a cada padrão tem-se

$$
R_{\text {medido }}=1,22 \pm 0,02 \quad \text { e } \quad R_{\text {calculado }}=1,22 \pm 0,03
$$

A tabela 4.3 apresenta os valores das atividades totais do ${ }^{210} \mathrm{~Pb}$ nas 21 amostras de solo analisadas, obtidos através da comparação com o padrão de quartzo moído e da comparação com o padrão de carbonato de cálcio. Os dois padrões forneceram valores coincidentes, de forma que, dentro dos erros experimentais, o procedimento de correção parece fornecer um resultado com boa exatidão. 
Tabela 4.3: Atividade total do ${ }^{210} \mathrm{~Pb}$, em Bq, estimada pela média das atividades calculados pelo método de correção da auto-absorção com os padrões secundários de ${ }^{210} \mathrm{~Pb}$ nas matrizes de $\mathrm{SiO}_{2}$ e de $\mathrm{CaCO}_{3}$.

$\begin{array}{llll}\text { Profundidade } & \text { Perfil no. } 1 & \text { Perfil no. } 2 & \text { Perfil no. } 3\end{array}$ (metros)

Atividade calculada com o padrão de $\mathrm{SiO}_{2}$

$\begin{array}{llll}0,00-0,30 & 16,6 \pm 0,9(\mathrm{~Bq}) & 19,2 \pm 0,9(\mathrm{~Bq}) & 12,2 \pm 0,8(\mathrm{~Bq}) \\ 0,30-0,60 & 14,0 \pm 1,0(\mathrm{~Bq}) & 17,5 \pm 0,9(\mathrm{~Bq}) & 14,6 \pm 0,9(\mathrm{~Bq}) \\ 0,60-0,90 & 12,6 \pm 0,9(\mathrm{~Bq}) & 15,3 \pm 0,8(\mathrm{~Bq}) & 14,2 \pm 0,8(\mathrm{~Bq}) \\ 0,90-1,20 & 12,3 \pm 0,8(\mathrm{~Bq}) & 13,4 \pm 0,9(\mathrm{~Bq}) & 12,9 \pm 0,8(\mathrm{~Bq}) \\ 1,20-1,50 & 13,6 \pm 0,8(\mathrm{~Bq}) & 13,1 \pm 0,8(\mathrm{~Bq}) & 14,9 \pm 0,8(\mathrm{~Bq}) \\ 1,50-1,80 & 12,1 \pm 0,8(\mathrm{~Bq}) & 14,8 \pm 0,8(\mathrm{~Bq}) & 10,9 \pm 0,8(\mathrm{~Bq}) \\ 1,80-2,10 & 12,5 \pm 0,8(\mathrm{~Bq}) & 14,4 \pm 0,9(\mathrm{~Bq}) & 14,1 \pm 0,8(\mathrm{~Bq})\end{array}$

Atividade calculada com o padrão de $\mathrm{CaCO}_{3}$

\begin{tabular}{llll}
$0,00-0,30$ & $16,6 \pm 0,9(\mathrm{~Bq})$ & $19,2 \pm 0,9(\mathrm{~Bq})$ & $12,2 \pm 0,8(\mathrm{~Bq})$ \\
$0,30-0,60$ & $14,0 \pm 1,0(\mathrm{~Bq})$ & $17,5 \pm 0,9(\mathrm{~Bq})$ & $14,6 \pm 0,9(\mathrm{~Bq})$ \\
$0,60-0,90$ & $12,6 \pm 0,9(\mathrm{~Bq})$ & $15,3 \pm 0,8(\mathrm{~Bq})$ & $14,2 \pm 0,8(\mathrm{~Bq})$ \\
$0,90-1,20$ & $12,3 \pm 0,8(\mathrm{~Bq})$ & $13,4 \pm 0,9(\mathrm{~Bq})$ & $12,9 \pm 0,8(\mathrm{~Bq})$ \\
$1,20-1,50$ & $13,6 \pm 0,8(\mathrm{~Bq})$ & $13,1 \pm 0,8(\mathrm{~Bq})$ & $14,9 \pm 0,8(\mathrm{~Bq})$ \\
$1,50-1,80$ & $12,1 \pm 0,8(\mathrm{~Bq})$ & $14,8 \pm 0,8(\mathrm{~Bq})$ & $10,9 \pm 0,8(\mathrm{~Bq})$ \\
$1,80-2,10$ & $12,5 \pm 0,8(\mathrm{~Bq})$ & $14,4 \pm 0,9(\mathrm{~Bq})$ & $14,1 \pm 0,8(\mathrm{~Bq})$ \\
\hline
\end{tabular}




\section{Perfis de atividade dos radionuclídeos das séries do urânio e do tório e atividade do ${ }^{40} \mathrm{~K}$ no solo}

\subsection{Atividade dos radionuclídeos da série do ${ }^{238} \mathrm{U}$}

A tabela 5.1 apresenta as atividades individuais do ${ }^{214} \mathrm{~Pb}$ e do ${ }^{214} \mathrm{Bi}$, calculadas com a equação 3.3 , obtidas comparando seus picos de absorção total com os respectivos picos do padrão secundário LGTSI05. A mesma tabela também mostra as estimativas de atividade do ${ }^{226} \mathrm{Ra}$ calculadas pela média ponderada das observações individuais da atividade dos seus produtos de decaimento, o ${ }^{214} \mathrm{~Pb}$ e o ${ }^{214} \mathrm{Bi}$, e os valores para a atividade do ${ }^{238} \mathrm{U}$, calculadas com a equação 3.7 , para cada intervalo de amostragem dos perfis de solo. Todas as observações de atividade ficaram acima do limite de detecção.

A tabela 5.1 também apresenta o resultado dos teste do $\chi^{2}$, aplicado à estimativa de atividade média dos radionuclídeos da série do urânio. O número esperado de rejeições é de apenas uma, para o nível de significância de 5\% com $n$ - 1 graus de liberdade. O número observado de rejeições foi quatro.

A determinação da atividade do ${ }^{210} \mathrm{~Pb}$ nos perfis é baseada nas medidas de solo não-perturbado pelo método de correção da absorção da energia de 46,5 keV, emitida pelo ${ }^{210} \mathrm{~Pb}$. As atividades totais e as concentrações de atividade obtidas para o ${ }^{210} \mathrm{~Pb}$ são apresentadas na tabela 5.2. 


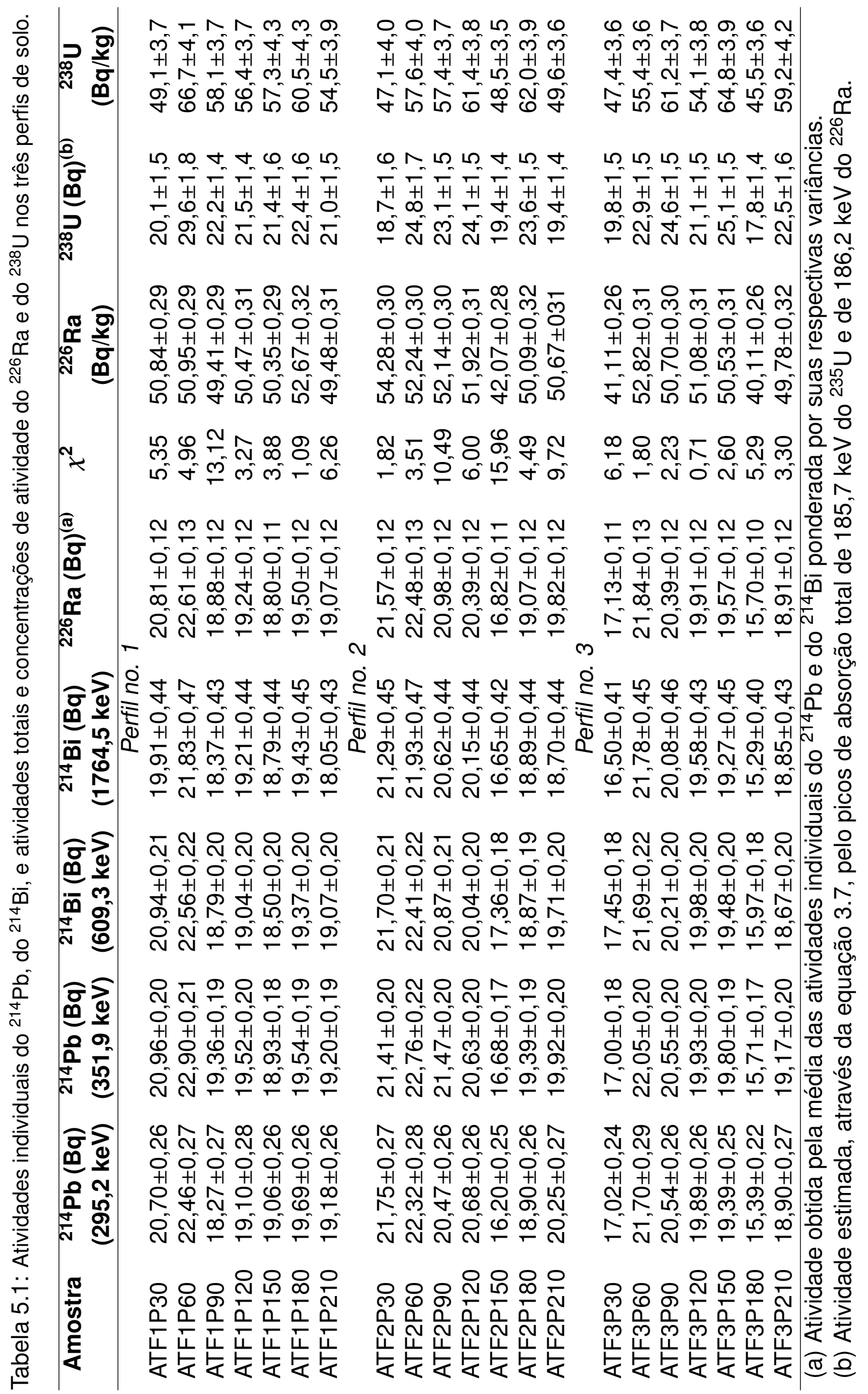


Tabela 5.2: Atividades totais e concentrações de atividade do ${ }^{210} \mathrm{~Pb}$ observados nas amostras de solo.

\begin{tabular}{cccc}
\hline $\begin{array}{c}\text { Profundidade } \\
\text { (metros) }\end{array}$ & $\begin{array}{c}\text { Massa } \\
(\mathrm{g})\end{array}$ & $\begin{array}{c}\text { Atividade } \\
\text { total }(\mathrm{Bq})\end{array}$ & $\begin{array}{c}\text { Concentração de } \\
\text { atividade }(\mathrm{Bq} / \mathrm{kg})\end{array}$ \\
\hline
\end{tabular}

Perfil no. 1

$\begin{array}{llll}0,00-0,30 & 409,292 \pm 0,005 & 16,6 \pm 0,9 & 41 \pm 2 \\ 0,30-0,60 & 443,778 \pm 0,005 & 14,0 \pm 1,0 & 32 \pm 2 \\ 0,60-0,90 & 382,123 \pm 0,005 & 12,6 \pm 0,9 & 33 \pm 2 \\ 0,90-1,20 & 381,235 \pm 0,005 & 12,3 \pm 0,8 & 32 \pm 2 \\ 1,20-1,50 & 373,195 \pm 0,005 & 13,6 \pm 0,8 & 36 \pm 2 \\ 1,50-1,80 & 370,225 \pm 0,005 & 12,1 \pm 0,8 & 33 \pm 2 \\ 1,80-2,10 & 385,435 \pm 0,005 & 12,5 \pm 0,8 & 32 \pm 2\end{array}$

Perfil no. 2

$\begin{array}{llll}0,00-0,30 & 397,375 \pm 0,005 & 19,2 \pm 0,9 & 48 \pm 2 \\ 0,30-0,60 & 430,340 \pm 0,005 & 17,5 \pm 0,9 & 40 \pm 2 \\ 0,60-0,90 & 402,720 \pm 0,005 & 15,3 \pm 0,8 & 38 \pm 2 \\ 0,90-1,20 & 392,720 \pm 0,005 & 13,4 \pm 0,9 & 34 \pm 2 \\ 1,20-1,50 & 399,763 \pm 0,005 & 13,1 \pm 0,8 & 33 \pm 2 \\ 1,50-1,80 & 380,720 \pm 0,005 & 14,8 \pm 0,8 & 39 \pm 2 \\ 1,80-2,10 & 391,187 \pm 0,005 & 14,4 \pm 0,9 & 37 \pm 2\end{array}$

Perfil no. 3

$\begin{array}{cccc}0,00-0,30 & 416,675 \pm 0,005 & 12,2 \pm 0,8 & 29 \pm 2 \\ 0,30-0,60 & 413,517 \pm 0,005 & 14,6 \pm 0,9 & 35 \pm 2 \\ 0,60-0,90 & 402,168 \pm 0,005 & 14,2 \pm 0,8 & 34 \pm 2 \\ 0,90-1,20 & 389,795 \pm 0,005 & 12,9 \pm 0,8 & 33 \pm 2 \\ 1,20-1,50 & 387,278 \pm 0,005 & - & - \\ 1,50-1,80 & 391,420 \pm 0,005 & - & - \\ 1,80-2,10 & 379,901 \pm 0,005 & 14,1 \pm 0,8 & 37 \pm 2\end{array}$

A figura 5.1 apresenta as concentrações dos radionuclídeos da série do urânio, o ${ }^{238} \mathrm{U}$, o ${ }^{226} \mathrm{Ra}$ e o ${ }^{210} \mathrm{~Pb}$ em função da profundidade dos perfis de solo. Nesta figura, os valores das concentrações correspondem à media dos valores observados a cada intervalo de 0,30 $\mathrm{m}$ de profundidade nos três perfis de atividade, exceto os intervalos de amostragem de 1,20 a 1,50 m e 1,50 a 1,80 m. Nessas profundidades os valores apresentados correspondem às médias dos dois primeiros perfis. A barra de erro vertical corresponde a um desvio padrão em torno do valor médio das atividades. 


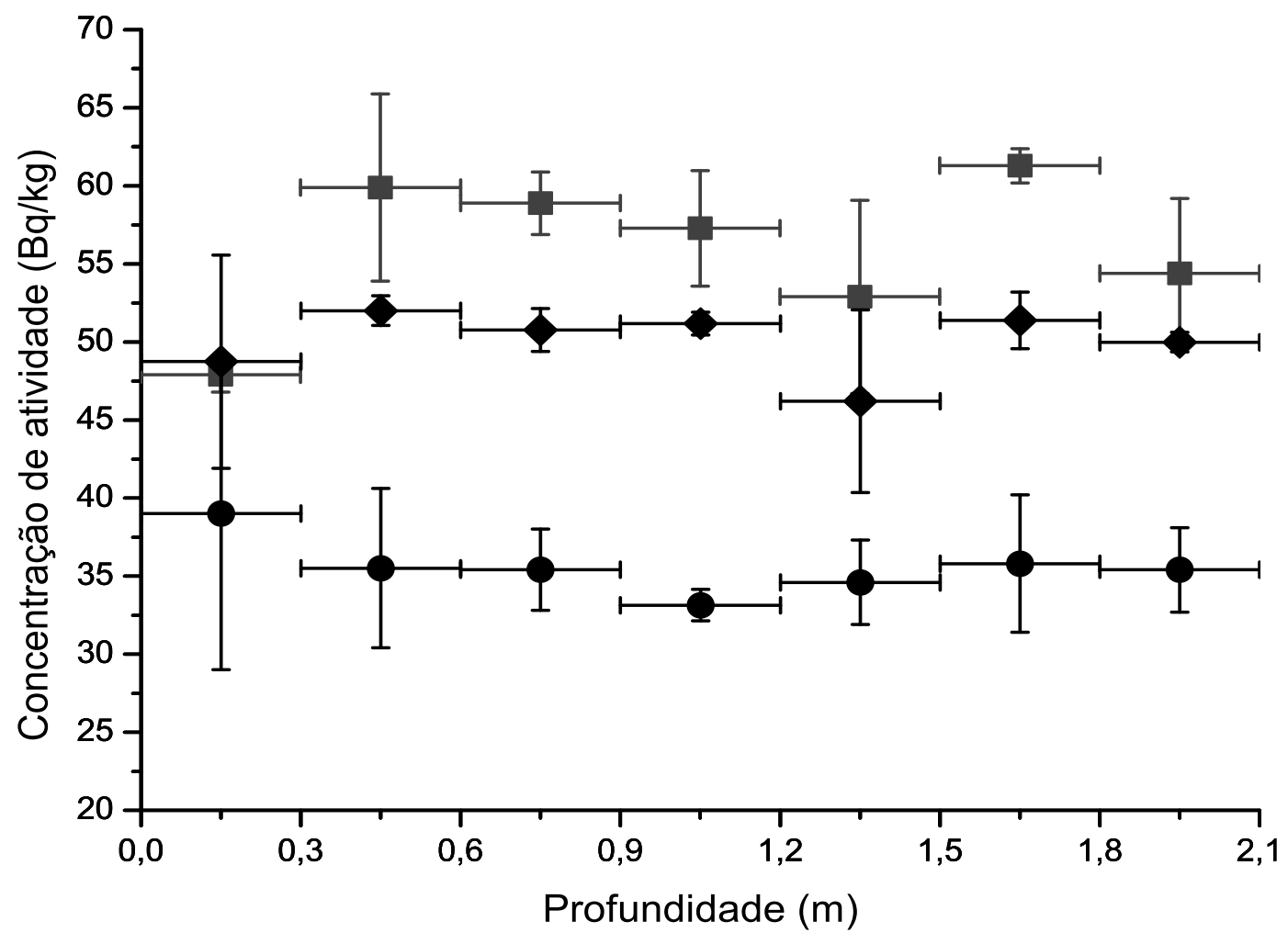

Figura 5.1: Concentrações de atividades do ${ }^{238} \mathrm{U}(\mathbf{\square})$, do ${ }^{226} \mathrm{Ra}(\bullet)$ e do ${ }^{210} \mathrm{~Pb}(\bullet)$, expressas em Bq/kg, como função da profundidade do perfil de solo.

As profundidades apresentadas nesta figura correspondem ao centro do intervalo de amostragem e a barra de erro horizontal representa a metade do comprimento total do intervalo, 0,15 m.

Para profundidades maiores que $0,30 \mathrm{~m}$ as concentrações dos três radionuclídeos mostraram uma pequena variação com a profundidade. As concentrações de ${ }^{238} U$ caem de um valor próximo a $60 \mathrm{~Bq} / \mathrm{kg}$ na transição do horizonte $\mathrm{A}$ para o horizonte $\mathrm{B}$, para valores próximos a $55 \mathrm{~Bq} / \mathrm{kg}$ em todo o horizonte $\mathrm{B}$. As concentrações do ${ }^{226} \mathrm{Ra}$ variam em valores em torno de $50 \mathrm{~Bq} / \mathrm{kg}$, enquanto as concentrações do ${ }^{210} \mathrm{~Pb}$ variam em torno de $35 \mathrm{~Bq} / \mathrm{kg}$.

A figura 5.2 apresenta as razões entre as atividades do ${ }^{226} \mathrm{Ra}$ e o ${ }^{238} \mathrm{U}$ e entre o ${ }^{210} \mathrm{~Pb}$ e o ${ }^{226} \mathrm{Ra}$ como função da profundidade. Para profundidades maiores que 
$0,30 \mathrm{~m}$ as taxas de atividade são menores que 1 , indicando que a série radioativa do urânio está em desequilíbrio radioativo em todo o horizonte $B$. $O{ }^{226} \mathrm{Ra}$ está reduzido em relação ao ${ }^{238} \mathrm{U}$ e o ${ }^{210} \mathrm{~Pb}$ está reduzido em relação ao ${ }^{226} \mathrm{Ra}$ neste horizonte.

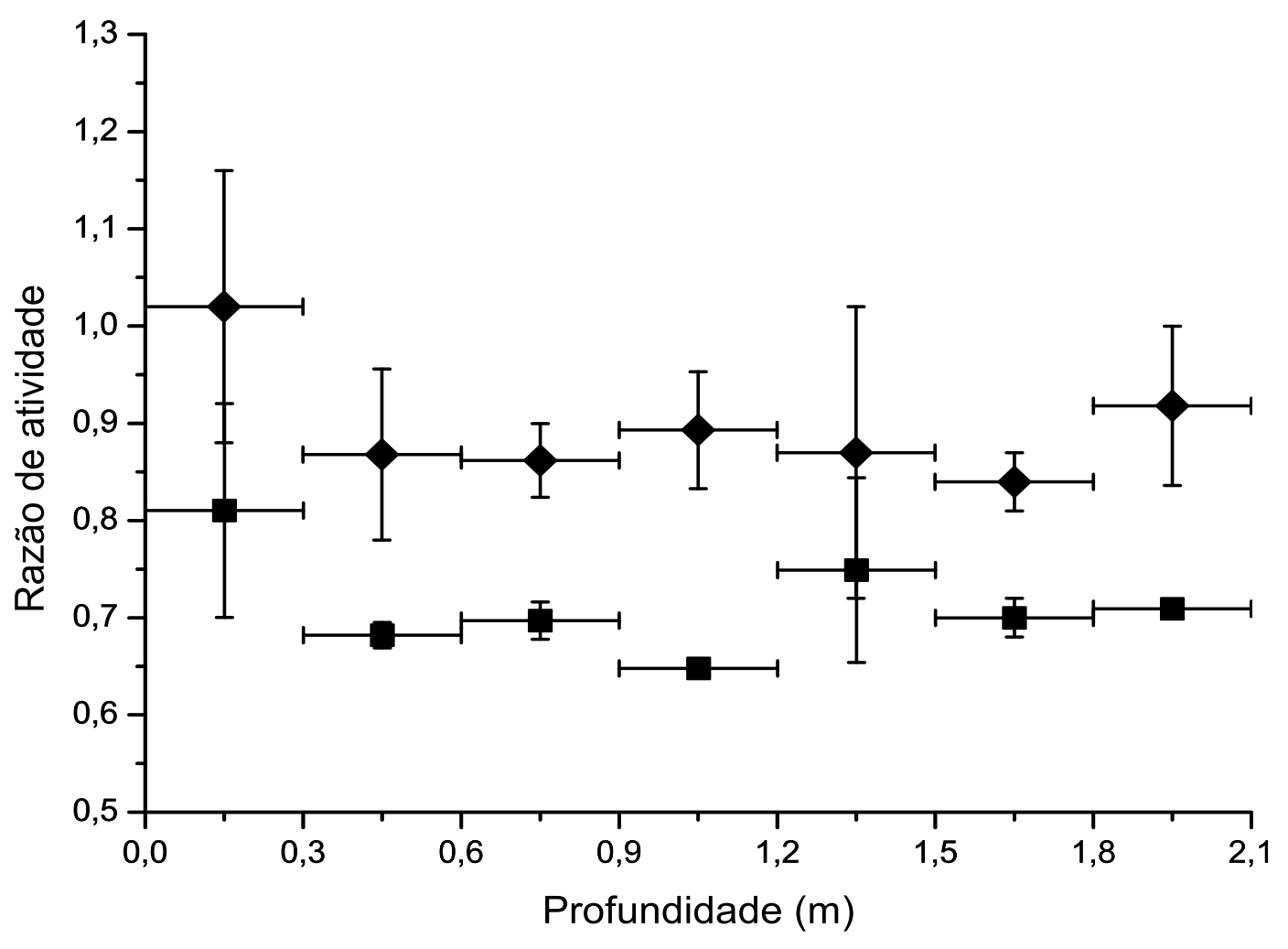

Figura 5.2: Razões de atividade ${ }^{226} \mathrm{Ra} /{ }^{238} \mathrm{U}(\bullet) \mathrm{e}^{210} \mathrm{~Pb} /{ }^{226} \mathrm{Ra}(\boldsymbol{\square})$ como função da profundidade do solo. A barra de erro vertical representa um desvio padrão, e a barra de erro horizontal a metade do intervalo de amostragem.

Na figura 5.3 são apresentadas as concentrações do ${ }^{210} \mathrm{~Pb}$ não suportado, em $\mathrm{Bq} / \mathrm{kg}$, definida como a diferença entre os valores observados e a concentração esperada, assumindo o equilíbrio radioativo secular entre o rádio e o chumbo, em função da profundidade. Estes valores indicam um empobrecimento do ${ }^{210} \mathrm{~Pb}$ em relação ao ${ }^{226} \mathrm{Ra}$ em todo o intervalo de solo amostrado. O empobrecimento é um pouco menor nos primeiros $0,30 \mathrm{~m}$ dos perfis, o que pode ser devido à precipitação do ${ }^{210} \mathrm{~Pb}$ presente na atmosfera.

O desequilíbrio observado entre o ${ }^{210} \mathrm{~Pb}$ e o ${ }^{226} \mathrm{Ra}$ pode ser explicado pelo es- 


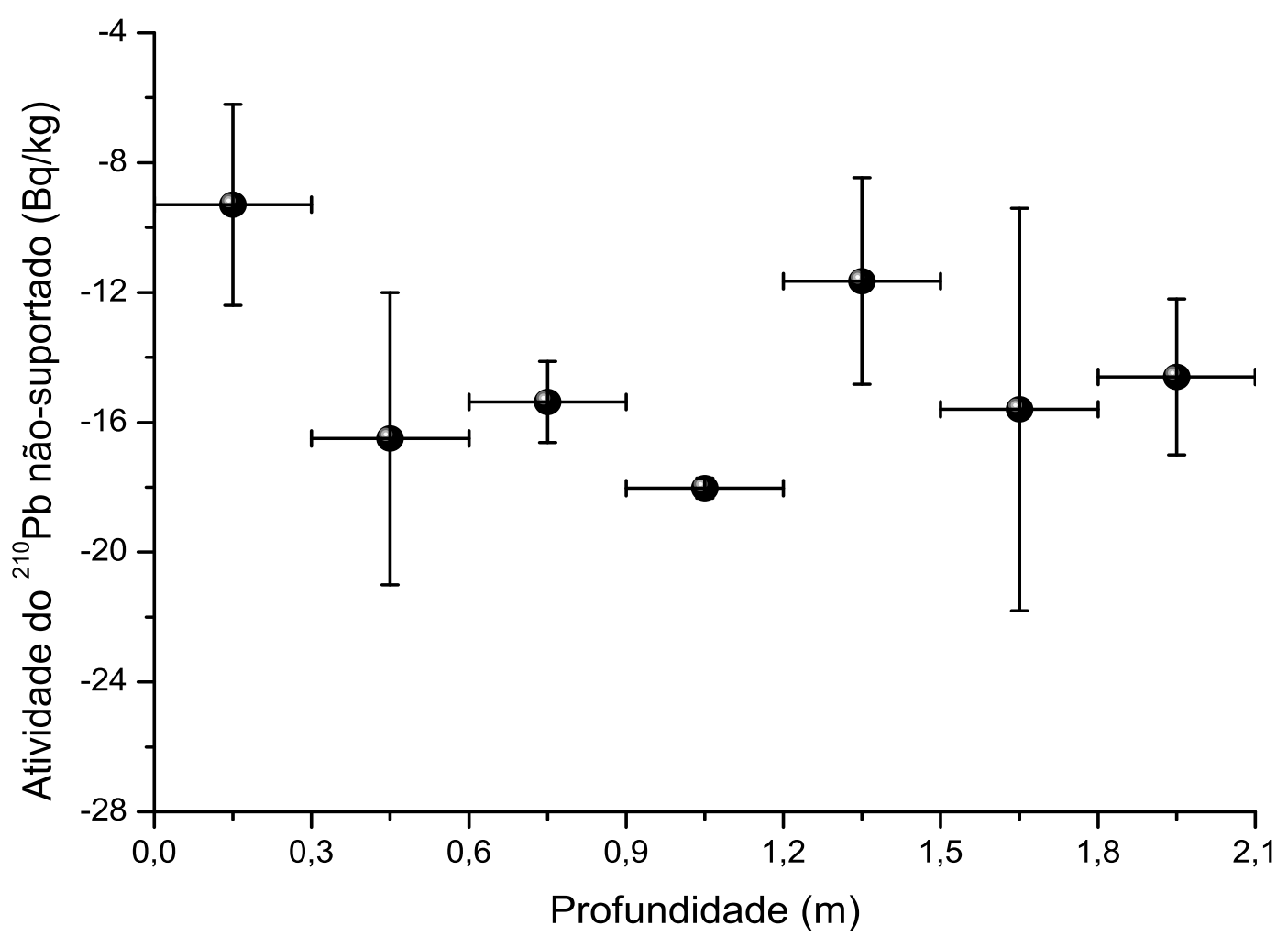

Figura 5.3: Concentração do ${ }^{210} \mathrm{~Pb}$ não-suportado, em Bq/kg, em função da profundidade do solo. A incerteza corresponde a um desvio padrão em torno da média.

cape do ${ }^{222} \mathrm{Rn}$ para a atmosfera. $\mathrm{O}{ }^{222} \mathrm{Rn}$ é um membro da série do urânio produzido pelo decaimento- $\alpha$ do ${ }^{226} \mathrm{Ra}$. Ele é um gás radioativo e inerte. Com uma meia-vida de cerca de 3,8 dias, o radônio entra no espaço de poro do solo por recuo direto devido ao decaimento- $\alpha$ do rádio e pode migrar em distâncias de vários metros no solo (TANNER, 1964, 1980). O radônio escapa para a atmosfera e seu decaimento origina uma seqüencia de isótopos de meia-vida curta (meia-vida menor que 27 minutos) e produz o ${ }^{210} \mathrm{~Pb}$. Este isótopo radioativo de chumbo associa-se a partículas aerosóis e a partículas de poeira e retorna para a superfície do solo por precipitação e deposição seca. A taxa de atividade ${ }^{210} \mathrm{~Pb} /{ }^{226} \mathrm{Ra}$ e o ${ }^{210} \mathrm{~Pb}$ não-suportado observados parecem refletir, ao menos em parte, este ciclo.

O perfil de concentração do ${ }^{226} \mathrm{Ra}$ observado e a razão de atividades entre o 
${ }^{226} \mathrm{Ra}$ e $\mathrm{o}{ }^{238} \mathrm{U}$ do perfil podem refletir, em parte, o processo de fracionamento da série de decaimento do urânio entre o ${ }^{238} \mathrm{U}$ e o ${ }^{234} \mathrm{U}$, onde o ${ }^{234} \mathrm{U}$ é transferido para o espaço de poro e conseqüentemente transportado pela água presente nos poros do solo. $\mathrm{A}$ distribuição do ${ }^{226} \mathrm{Ra}$ observada no perfil de $2,10 \mathrm{~m}$ de profundidade pode também refletir a absorção do rádio pela vegetação da Mata Atlântica durante um período de tempo muito longo e muito anterior a qualquer interferência humana significativa na floresta (GREEMAN et al., 1999).

\subsection{Atividade dos radionuclídeos da série do ${ }^{232} \mathrm{Th}$}

A tabela 5.3 apresenta as atividades individuais do ${ }^{228} \mathrm{Ac}$, do ${ }^{208} \mathrm{Tl}$ e as atividades totais do ${ }^{228} \mathrm{Ra}$, do ${ }^{228} \mathrm{Th}$ e do ${ }^{232} \mathrm{Th}$ para os três perfis de solo. As atividades do ${ }^{228} \mathrm{Ra}$ e do ${ }^{228}$ Th são representados pelas atividades dos seus produtos de decaimento de meia-vida curta, $\mathrm{O}^{228} \mathrm{Ac}$ e $\mathrm{O}^{208} \mathrm{TI}$ respectivamente, desde que estabelecido o equilíbrio radioativo secular entre eles. A atividade do ${ }^{228}$ Ra foi calculada como sendo a média das estimativas de atividades do ${ }^{228} \mathrm{Ac}$, feita através dos seus picos de absorção total de $911,2 \mathrm{keV}$ e de $969 \mathrm{keV}$ de energia, e através da média das estimativas individuais de atividade do ${ }^{208} \mathrm{TI}$, calculada pelos picos de absorção total de $583,2 \mathrm{keV}$ e de $860,6 \mathrm{keV}$ de energia, foi calculada a atividade do ${ }^{228} \mathrm{Th}$. No cálculo das atividades foi adotado o mesmo procedimento adotado para a série do urânio, porém, utilizando-se o padrão de atividade LTGSI06.

As concentrações observadas do ${ }^{228} \mathrm{Th}$ e do ${ }^{228} \mathrm{Ra}$ permitiram a estimativa da razão de atividade ${ }^{228} \mathrm{Th} /{ }^{228} \mathrm{Ra}$ em torno de 1 para toda a camada de solo amostrado. Como esses dois isótopos possuem meias-vidas não muito distintas, 5,75 anos para o ${ }^{228} \mathrm{Ra}$ e 1,91 anos para $0{ }^{228} \mathrm{Th}$, a taxa de atividade estimada indica que os dois isótopos, e toda a série radioativa a que pertencem, estão em equilíbrio radioativo secular com o ${ }^{232} \mathrm{Th}$. Portanto, a atividade do ${ }^{232} \mathrm{Th}$ pode ser fornecida pela média ponderada das atividades individuais de cada pico de absorção total dos radionuclídeos 
escolhidos pertencentes à sua série radioativa.

A atividade do ${ }^{232}$ Th pode ser estimada pela média das estimativas de atividade do ${ }^{228} \mathrm{Ac}$ e do ${ }^{208} \mathrm{TI}$, ponderada por suas respectivas variâncias. $\mathrm{O}$ teste do $\chi^{2}$ quando aplicado às estimativas de atividade do ${ }^{232}$ Th não apresentou nenhum valor fora do intervalo de confiança de 0,95.

A figura 5.4 apresenta a variação dos valores de concentração da atividade do ${ }^{232} \mathrm{Th}$ como função da profundidade. A concentração do ${ }^{232} \mathrm{Th}$ cresce de $80 \mathrm{~Bq} / \mathrm{kg}$, no horizonte $\mathrm{O}$, para um valor próximo a $110 \mathrm{~Bq} / \mathrm{kg}$, no horizonte $\mathrm{B}$.

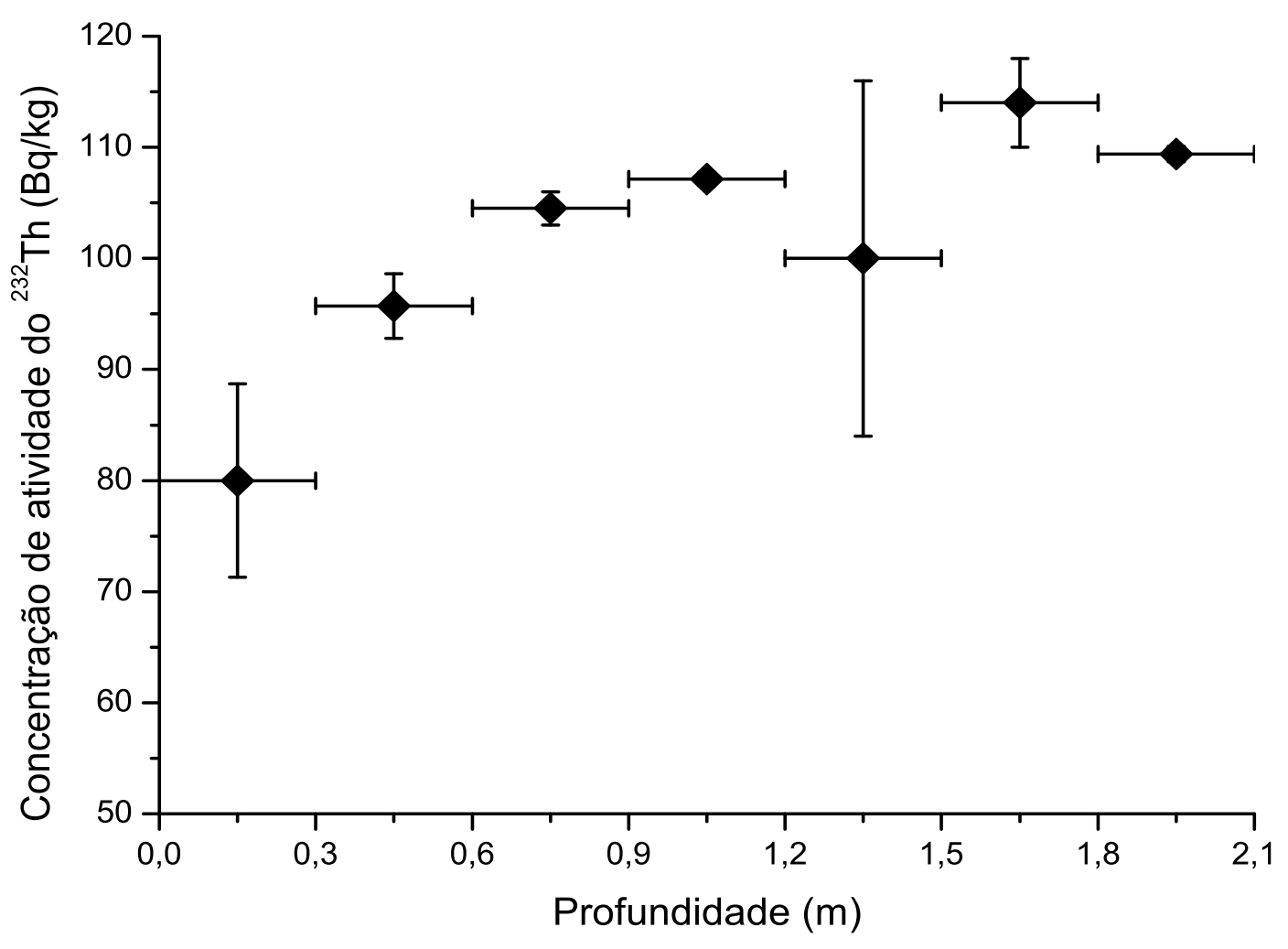

Figura 5.4: Concentrações de atividade do ${ }^{232}$ Th como função da profundidade do solo. 


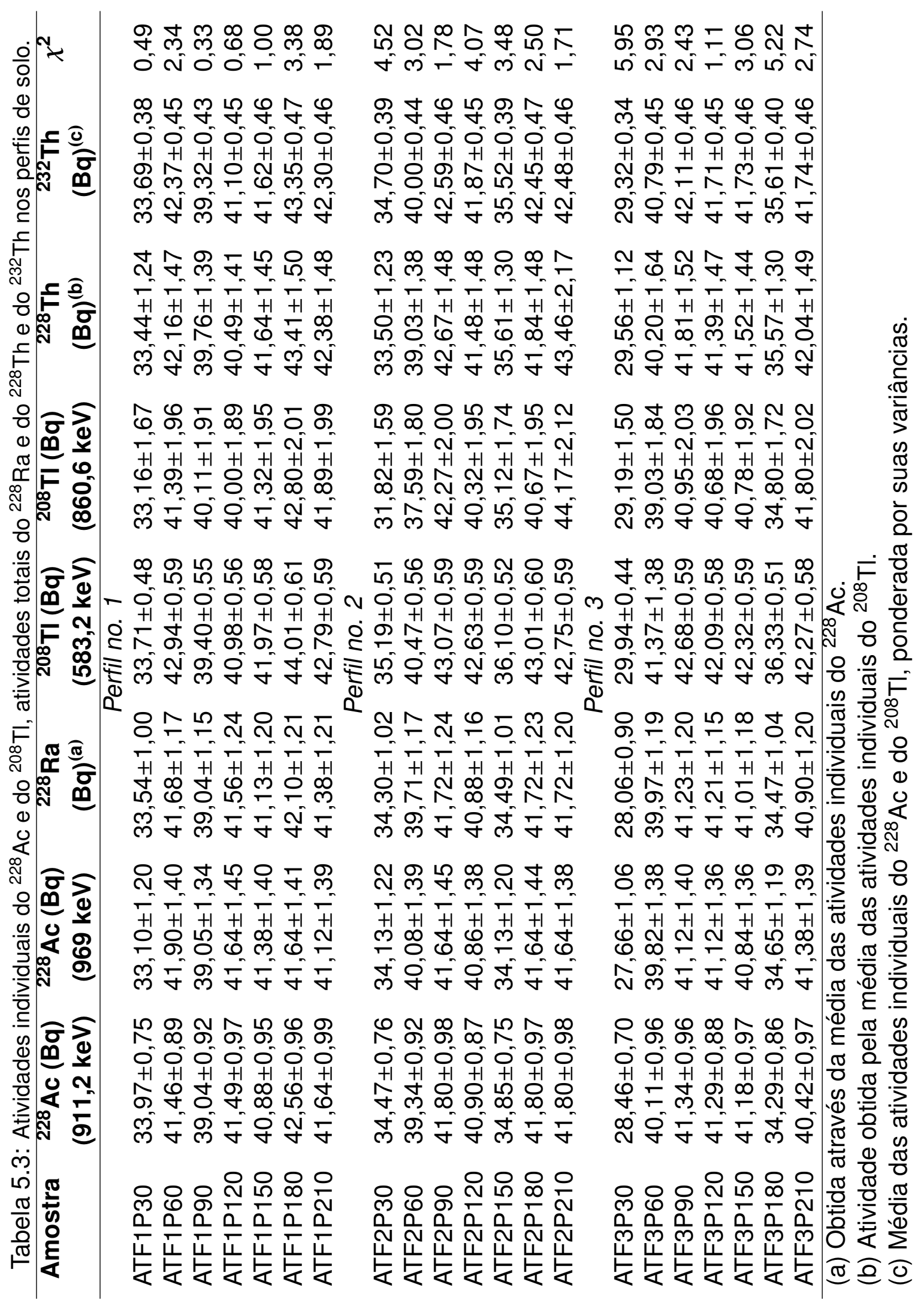




\subsection{Atividade do ${ }^{40} \mathrm{~K}$ no solo}

A tabela 5.4 apresenta as medidas de atividade do ${ }^{40} \mathrm{~K}$ nas amostras de solo analisadas. Os resultados mostram uma grande variação nas atividades desse isótopo, com amostras abaixo do limite de detecção, em algumas profundidades. $O$ valor máximo de atividade observado foi de $37,8 \pm 2,4 \mathrm{~Bq} / \mathrm{kg}$, o que corresponde a uma concentração de potássio de 0,119 $\pm 0,008$ \% em massa.

Tabela 5.4: Atividades totais, concentrações de atividade e concentrações em porcentagem de massa do ${ }^{40} \mathrm{~K}$ nas amostras de solo.

\begin{tabular}{|c|c|c|c|c|}
\hline Amostra & Massa & $\begin{array}{l}\text { Atividade } \\
\text { total } \\
(\mathrm{Bq})\end{array}$ & $\begin{array}{c}\text { Concentração } \\
\text { de atividade } \\
(\mathrm{Bq} / \mathrm{kg})\end{array}$ & (\% em massa) \\
\hline \multicolumn{5}{|c|}{ Perfil no. 1} \\
\hline ATF1P30 & $409,292 \pm 0,005$ & $8,83 \pm 0,96$ & $21,57 \pm 2,35$ & $0,068 \pm 0,007$ \\
\hline ATF1P60 & $443,778 \pm 0,005$ & $16,22 \pm 1,02$ & $36,55 \pm 2,30$ & 0,007 \\
\hline ATF1P90 & $382,123 \pm 0,005$ & $2,25 \pm 0,93$ & $5,89 \pm 2,43$ & $0,018 \pm 0,008$ \\
\hline ATF1P120 & $381,235 \pm 0,005$ & $1,08 \pm 0,95$ & $2,83 \pm 2,49$ & $0,009 \pm 0,008$ \\
\hline ATF1P150 & $373,195 \pm 0,005$ & $2,34 \pm 0,92$ & $6,27 \pm 2,46$ & $0,020 \pm 0,008$ \\
\hline ATF1P180 & $370,225 \pm 0,005$ & $6,23 \pm 0,95$ & $16,83 \pm 2,57$ & $0,053 \pm 0,008$ \\
\hline ATF1P210 & $385,435 \pm 0,005$ & $\begin{array}{r}11,35 \pm 1,00 \\
\text { Perfil no. } 2\end{array}$ & $29,45 \pm 2,59$ & $0,093 \pm 0,008$ \\
\hline ATF2P30 & $397,375 \pm 0,005$ & $12,40 \pm 0,98$ & $21 \pm 2,47$ & $8 \pm 0,008$ \\
\hline ATF2P60 & $430,340 \pm 0,005$ & $16,15 \pm 0,98$ & $37,53 \pm 2,28$ & 0,007 \\
\hline ATF2P90 & $402,720 \pm 0,005$ & $12,58 \pm 0,97$ & $7 \pm 2,41$ & $98 \pm 0,008$ \\
\hline ATF2P120 & $392,720 \pm 0,005$ & $8,47 \pm 0,96$ & $21,57 \pm 2,44$ & $0,068 \pm 0,008$ \\
\hline ATF2P150 & $399,763 \pm 0,005$ & I. d. & & \\
\hline ATF2P180 & $380,720 \pm 0,005$ & $12,33 \pm 0,99$ & $39 \pm 2,60$ & $02 \pm 0,008$ \\
\hline ATF2P210 & $391,187 \pm 0,005$ & $\begin{array}{r}14,66 \pm 0,98 \\
\text { Perfil no. } 3\end{array}$ & $37,48 \pm 2,51$ & $0,118 \pm 0,008$ \\
\hline ATF3P30 & $416,675 \pm 0,005$ & I. d. & - & - \\
\hline ATF3P60 & $413,517 \pm 0,005$ & $15,64 \pm 1,01$ & $37,82 \pm 2,44$ & $0,119 \pm 0,008$ \\
\hline ATF3P90 & $402,168 \pm 0,005$ & $4,97 \pm 0,94$ & $12,36 \pm 2,34$ & $0,039 \pm 0,007$ \\
\hline ATF3P120 & $389,795 \pm 0,005$ & $4,97 \pm 0,95$ & $12,75 \pm 2,44$ & $0,040 \pm 0,008$ \\
\hline ATF3P150 & $387,278 \pm 0,005$ & $6,20 \pm 0,95$ & $16,01 \pm 2,45$ & $0,050 \pm 0,008$ \\
\hline ATF3P180 & $391,420 \pm 0,005$ & I. d. & - & - \\
\hline ATF3P210 & $379,901 \pm 0,005$ & $7,00 \pm 0,96$ & $18,43 \pm 2,53$ & $0,058 \pm 0,008$ \\
\hline
\end{tabular}

l. d. - Atividade abaixo do limite de detecção. 


\section{Conclusão}

As atividades dos radionuclídeos das séries do urânio, da série do tório, além da atividade do ${ }^{40} \mathrm{~K}$, foram medidas, utilizando-se a espectrometria- $\gamma$ natural, em um solo não-perturbado retirados de uma área de Mata Atlântica localizada no Jardim Botânico da Secretaria de Meio Ambiente do Estado de São Paulo. Esta reserva se caracteriza por ser uma área livre da ação do homem há bastante tempo e, portanto, capaz de refletir o ciclo natural destes elementos. No local de coleta, o solo não tem sofrido ação humana direta desde, pelo menos, 1938. O solo foi amostrado em três furos feitos com trado manual, dispostos em um arranjo triangular com 1 metro de lado. As amostras foram retiradas em intervalos de $0,30 \mathrm{~m}$ e o comprimento total amostrado foi de $2,10 \mathrm{~m}$.

As atividades do ${ }^{210} \mathrm{~Pb}$, nos perfis de solo, obtidas de forma independente a partir dos padrões secundários de atividade de ${ }^{210} \mathrm{~Pb}$ nas matrizes de $\mathrm{SiO}_{2}$ e de $\mathrm{CaCO}_{3}$ são bem ajustados, dentro da estimativa do erro de cada uma das medidas, e mostraram que o método desenvolvido é bastante eficiente na correção do efeito da autoabsorção da radiação- $\gamma$ de 46,5 keV de energia emitida pelo ${ }^{210} \mathrm{~Pb}$.

As medidas de atividade do ${ }^{238} \mathrm{U}$ do ${ }^{226} \mathrm{Ra}$ e do ${ }^{210} \mathrm{~Pb}$ apresentaram uma pequena variação com a profundidade do solo. A atividade específica do ${ }^{226} \mathrm{Ra}$ praticamente não varia ao longo dos 2,10 m de perfil de solo, enquanto que a atividade do ${ }^{210} \mathrm{~Pb}$ decresce levemente dos horizontes $\mathrm{O}$ e $\mathrm{A}$ para o horizonte $\mathrm{B}$. A atividade específica do ${ }^{238} U$ é pouco variável no horizonte $B$ e superior à atividade observada nos horizontes $\mathrm{O}$ e $\mathrm{A}$, refletindo, muito provavelmente, a distribuição de minerais de 
argila no solo.

A série do urânio está em desequilíbrio em toda a camada de solo amostrada com razões de atividade ${ }^{226} \mathrm{Ra} /{ }^{238} \mathrm{U}$ da ordem de 0,9 para profundidades superiores a $0,30 \mathrm{~m}$ e com razões de atividade de ${ }^{210} \mathrm{~Pb} /{ }^{226} \mathrm{Ra}$ com valores da ordem de 0,7 no mesmo intervalo de profundidades. A causa do desequilíbrio na série do urânio não pode ser estabelecida com base nos dados disponíveis. No entanto, pode-se especular que o desequilíbrio ${ }^{210} \mathrm{~Pb} /{ }^{226} \mathrm{Ra}$ seja devido, principalmente ao escape do ${ }^{222} \mathrm{Rn}$ para o espaço de poro, seguindo, em parte, da sua difusão para a atmosfera e, em parte, do seu transporte pela água de solo.

A série do tório está em equilíbrio radioativo secular e a distribuição da atividade do ${ }^{232}$ Th reflete, como no caso do ${ }^{238} \mathrm{U}$, a distribuição de minerais de argila no solo.

O perfil de atividade do ${ }^{40} \mathrm{~K}$ apresenta uma grande variação ao longo da camada de solo. 


\section{Referências Bibliográficas}

ABRAMOWITZ, M.; STEGUN, I. A. Handbook of mathematical functions. New York: Dover Publications, 1965.

APPLEBY, P. G.; RICHARDSON, N.; NOLAN, P. J. Self-absorption for well-type germanium detectors. Nuclear Instruments and Methods in Physics Research B, v. 71, p. 228-233, 1992.

BENNINGER, L. K.; LEWIS, D. M.; TUREKIAN, K. K. The use of natural ${ }^{210} \mathrm{~Pb}$ as a heavy metal tracer in the river estuarine system. In: $\mathrm{CHURCH}$, T. M. (Ed.). Marine Chemistry, Amer. Chem. Soc. Monogr. Washington, D. C.: American Chemical Society, 1975.

BOLIVAR, J. P.; GARCIA-TENORIO, R.; GARCIA-LEON, M. A method for determination of counting efficiencies in $\gamma$-spectrometric measurements with HPGe detectors. Nucle. Instrum. Methods A, n. 206, p. 495-502, 1996.

COCCO, G.; FONFANI, L.; ZANAZZI, P. F. Potassium. In: WEDEPOHL K. H. ; SHAW, D. M.; TUREKIAN, K. K.; ZEMANN, J. (Ed.). Handbook of Geochemistry. Berlin: Springer-Verlag, 1978. II-2.

CURRIE, L. A. Limits for qualitative detection and quantitative determination application to radiochemistry. Analytical Chemistry, v. 40, p. 586-593, 1968.

CUTSHALL, N. H.; LARSE, I. L.; OLSEN, C. R. Direct analysis of ${ }^{210} \mathrm{~Pb}$ in sediment samples: self-absorption corrections. Nuclear Instruments and Methods, v. 206, p. 309-312, 1983.

DEBERTIN, K.; HELMER, R. G. Gamma and $x$-ray spectrometry with semiconductor detectors. New York: North Holland, 1988.

EDSFELDT, C. The radium distribution in some Swedish soils and its effect on radon emanation. Tese (Doutorado) - Division of Engineering Geology. Department of Civil and Enviromental Engineering. Royal Institute of Technology, Stockholm, 2001.

EVANS, R. D. The Atomic Nucleus. New York: McGraw Hill, 1955.

FISENNE, I. M. Distribution of lead-210 and radium-228 in soil. In: Rep. UCRL-18140. Washington, D. C.: U. S. At. Energy Comm., 1968. p. 145-158.

FLEISCHER, R. L. Alpha-recoil damage and solution effects in minerals: uranium isotopic disequilibrium and radon release. Geochimica et Cosmochimica Acta, n. 46, p. 2191-2201, 1982. 
FLEISCHER, R. L. Alpha-recoil damage: Relation to isotopic disequilibrium and leaching of radionuclides. Geochimica et Cosmichimica Acta, n. 52, p. 1459-1466, 1988.

GALLOWAY, R. B. Corrections for sample self-absorption in activity determination by gamma spectrometry. Nuclear Instruments and Methods in Physics Research A, v. 300, p. 367-373, 1991.

GREEMAN, D. J.; ROSE, A. W. Factors controlling the emanation of radon and thoron in soils of the eastern USA. Chemical Geology, n. 129, p. 1-14, 1996.

GREEMAN, D. J.; ROSE, A. W.; JESTER, W. A. Form and behavior of radium, uranium, and thorium in Central Pensylvania soils derived from dolomite. Geophysical Research Letters, n. 17, p. 833-836, 1990.

GREEMAN, D. J. et al. Geochemistry of radium in soils of the Eastern United States. Applied Geochemistry, n. 14, p. 365-385, 1999.

HEIER, K. S.; BILLINGS, G. K. Potassium. In: WEDEPOHL K. H.; SHAW, D. M.; TUREKIAN, K. K.; ZEMANN, J. (Ed.). Handbook of Geochemistry. Berlin: Springer-Verlag, 1978. II-2.

HUSSAIN, N. et al. A simplified tecnique for gamma-spectrometric analyis of ${ }^{210} \mathrm{~Pb}$ in sediment samples. Applied Radiation Isotopes, v. 47, n. 4, p. 473-477, 1996.

IMOBODEN, D. M.; STILLER, M. The influence of radon diffusion on the ${ }^{210} \mathrm{~Pb}$ distribution in sediments. Journal of Geophysical Research, v. 87, p. 557-565, 1982.

IVANOVICH, M.; HARMON, R. S. Uranium-series Disequilibrium. Applications to Earth, Marine and Enviromental Problems. Second. Oxford: Clarendon Press, 1992.

IYENGAR, M. A. R. The natural distribution of radium. In: The enviromental behaviour of radium. Vienna: International Atomic Energy Agency, 1990, (IAEA Technical Report Series, 310). p. 59-128.

JAWOROWSKI, W. Sources and the global cycle of radium. In: The enviromental behaviour of radium. Vienna: International Atomic Energy Agency, 1990, (IAEA Technical Report Series, 310). p. 129-142.

JUNGE, C. E. Air Chemistry and Radioactivity. New York: Academic Press, 1963. (International Geophysics Series, v. 4).

KIGOSHI, K. Alpha-recoil ${ }^{234}$ Th: Dissolution into water and the ${ }^{234} \mathrm{U} /{ }^{238} \mathrm{U}$ disequilibrium in nature. Science, v. 173, p. 47-48, 1971.

KOGAN, R.; NAZAROV, I. M.; FRIDMAN, S. D. Gamma spectrometry of natural enviroments and formations. Israel Program for Scientific Tranlations. [S.I.]: LTD, 1971.

KRISHNASWAMI, S. et al. Radium, thorium and radioactive lead isotopes in groundwaters: Application to the in situ determiantion of adsorption-desorption rate constants and retardation factors. Water Resouce Research, v. 18, p. 1633-1675, 1982. 
LANGMUIR, D. Uranium solution-mineral equilibria at low temperatures with applications to sedimentary ore deposits. Geochimica et Cosmochimica Acta, n. 42, p. 547-569, 1978.

LANGMUIR, D.; HERMAN, J. S. The mobility of thorium in natural waters at low temperatures. Geochimica et Cosmochimica Acta, n. 44, p. 1753-1766, 1980.

LINSALATA, P. Uranium and thorium decay series radionuclides in human and animal foodchains - a review. J. of Envir. Quality, n. 23, p. 633-642, 1994.

MARTELL, E. A.; MOORE, H. E. Tropospheric aerosol residence times: a critical review. J. Res. Atmos., v. 8, p. 903-100, 1974.

MEGUMI, K.; MAMURO, T. Emanation and exhalation of radon and thoron gases from soil particles. Journal of Geophysical Research, v. 79, n. 23, p. 3357-3360, 1974.

MIGUEL, E. G. S. et al. ${ }^{210} \mathrm{~Pb}$ determiantion by gamma spectrometry in volumial samples (cylindrical geometry). Nuclear Instruments and Methods in Physics Research A, v. 493, p. 111-120, 2002.

MOLINARI, J.; SNODGRASS, W. J. The chemistry and radiochemistry of radium and the other elements of the uranium and thorium natural decay series. In: The enviromental behaviour of radium. Vienna: International Atomic Energy Agency, 1990, (IAEA Technical Report Series, 310). p. 11-56.

MOORE, H. E.; POET, S. E. ${ }^{210} \mathrm{~Pb}$ fluxes determined from ${ }^{210} \mathrm{~Pb}$ and ${ }^{226} \mathrm{Ra}$ soil profiles. Journal of Geophysical Research, v. 81, n. 06, p. 1056-1058, 1976.

MOORE, H. E.; POET, S. E.; MARTELL, E. A. ${ }^{222} \mathrm{Rn},{ }^{210} \mathrm{~Pb},{ }^{210} \mathrm{Bi}$ and ${ }^{210} \mathrm{Po}$ profiles and aerosol residence times versus altitude. Journal of Geophysical research, v. 78, n. 30, p. 7065-7075, 1973.

NATIONAL COUNCIL ON RADIATION PROTECTION. Ionizing radiation exposure of the population of the United States. In: NCRP Rept. 93. Bethesda, M. D.: NCRP, 1987.

NAZAROFF, W. W. Radon transport from soil to air. Reviews of Geophysics, v. 30, p. 137-160, 1992.

POET, S. E.; MOORE, H. E.; MARTELL, E. A. Lead-210, bismuth-210 and polonium-210 in the atmosphere: acurate ratio measurement and application to aerosol residence time determination. J. Geophys. Res., v. 77, p. 6515-6527, 1972.

PRESS, W. H. et al. Numerical Recipes: The art of scientific computing. Cambridge: Cambridge University Press, 1986.

RANGARAJAN, C. A study of the mean residence time of the natural radioactive aerosols in the planetary boudary layer. Journal of Envir. Radioactivity, v. 15, n. 3, p. 193-206, 1992.

REBELO, A. M. A.; BITTENCOUT, A. V. L.; MANTOVANI, L. E. Anomalias geoquímicas de $\mathrm{U}$ e de $\mathrm{Th}$, solos residuais e geoformas em paisagens tropicais úmidas sobre granito. Boletim Paranaense de Geociências, v. 51, p. 33-44, 2002. 
RIBEIRO, F. B. et al. Uranium and thorium series disequilibrium in quaternary carbonate deposits from the Serra da Bodoquena and Pantanal do Miranda, Mato Grosso do Sul State, Central Brazil. Applied Radiation and Isotopes, v. 54, p. 153-173, 2001.

SECRETARIA DE MEIO AMBIENTE DO ESTADO DE SÃO PAULO. Instituto de Botânica: Jardim Botânico . São Paulo, Acesso em: 15 fev. 2006. Disponível em: $<$ http://www.ibot.sp.gov.br/jardimbot/sobreojardim.htm>.

SEMKOW, T. M. Recoil-emanation theory applied to radon release from minerals grains. Geochimica et Cosmochimica Acta, 1990.

SEMKOW, T. M.; PAREK, P. P. The role of radium distribution and porosity radon emanation from solids. Geophysical Research Letters, v. 17, p. 837-840, 1990.

SUN, H.; SEMKOW, T. M. Mobilization of thorium, radium and radon radionuclides in groundwater by sucessive alpha-recoils. Journal of Hydrology, v. 205, p. 126-136, 1997.

TANNER, A. B. Radon migration in the ground: A review. In: ADAMS, J. A. S.; LOWDER, W. M. (Ed.). The Natural Radiation Enviroment Symposium. Chicago: University of Chicago Press, 1964. p. 161-190.

TANNER, A. B. Radon migration in the ground: A suplementary review. In: GESSELL, T. F.; LOWDER, W. M. (Ed.). Natural Radiation Enviroment III. Washington, D. C.: Dep. of Energy, 1980. p. 5-56.

TUREKIAN, K. K.; NOZAKI, Y.; BENNINGER, L. K. Geochemistry of atmospheric radon and radon products. Ann. Rev. Earth Planet Sci., v. 5, p. 227-255, 1977.

VARGAS, M. J. et al. Monte Carlo simulation of the self-absorption corrections for natural samples im gamma-ray spectrometry. Applied Radiiation and Isotopes, n. 57, p. 893-898, 2002.

VUOLO, J. H. Fundamentos da teoria dos erros. 2nd. ed. [S.I.]: Editora Edgard Blucher LTDA., 1996.

WARNECK, P. Chemistry of the natural atmosphere. San Diego. California.: Academic Press, 2000.

WASHINGTON, J. W.; ROSE, A. W. Regional and temporal relations of radon in soil gas to soil temperature and moisture. Geophysical Research Letters, n. 17, p. 829-832, 1990.

WASHINGTON, J. W.; ROSE, A. W. Temporal variability of radon concentration in the interstitial gas of soils in Pensylvania. Journal of Geophysical Research, n. 97(B6), p. 9145-9159, 1992. 


\section{APÊNDICE A - Modelo teórico para a correção do efeito de auto-absorção da radiação do ${ }^{210} \mathrm{~Pb}$ - parte I}

A correção do efeito de auto-absorção da radiação- $\gamma$ com 46,5 keV de energia pela matriz estéril de uma fonte que contém ${ }^{210} \mathrm{~Pb}$ homogêneamente disperso foi feita, neste trabalho, utilizando-se as equações 4.1, 4.2 e 4.5. Neste apêndice, será descrito o modelo que deu origem à equação 4.1 e a simplificação que permitiu a obtenção da equação 4.2. O modelo que levou à obtenção da equação 4.5 será descrito no apêndice B.

\section{A.1 A equação para estimativa do coeficiente de ate- nuação linear $\mu$}

A figura 4.1 é reproduzida abaixo, como figura A.1, para simplificar a leitura do desenvolvimento que segue.

As hipóteses fundamentais do modelo a ser desenvolvido são:

a) O efeito de atenuação ocorre exclusivamente na amostra, ou no padrão. Os efeitos de atenuação da radiação na solução que contém o ${ }^{210} \mathrm{~Pb}$, nos invólucros dos diferentes componentes do arranjo experimental e no ar contido nas espessuras $e_{1} e$ $\mathrm{e}_{2}$, são desprezados.

b) A interação da radiação- $\gamma$ com o material contido na caixa porta-amostra, absorção por efeito fotoelétrico ou espalhamento Compton, removem o fóton do feixe de 


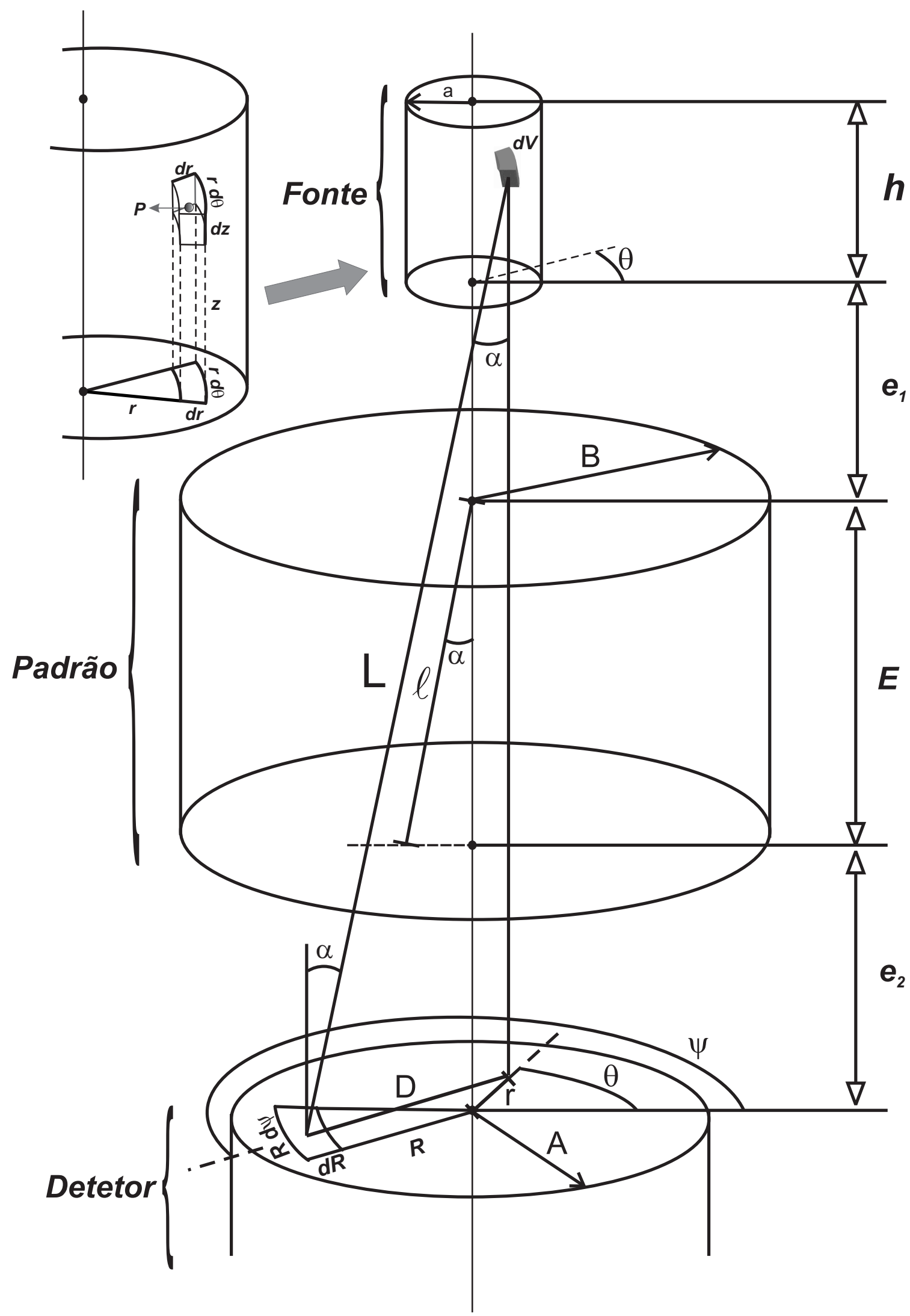

Figura A.1: Geometria para o ângulo sólido de um fóton incidente sobre a superfície do detector quando emitido por um padrão radioativo secundário localizado sobre a amostra de solo . 
radiação proveniente da fonte, de forma que apenas a radiação primária é registrada no pico de absorção total com energia de $46,5 \mathrm{keV}$ característico do ${ }^{210} \mathrm{~Pb}$. Essa hipótese será objeto de crítica no final ao apêndice B.

Observando o esquema da figura A.1, considere o ponto $P$ no interior da fonte de ${ }^{210} \mathrm{~Pb}$ com coordenadas cilíndricas $z, r$ e $\theta$, com $z$ contado a partir da base da fonte, que varia de 0 a $h, r$, sendo a distância do ponto ao eixo da fonte, que varia de 0 a $a$, e $\theta$ o ângulo azimutal contado a partir de uma referência escolhida de forma arbitrária.

Considere também o elemento de área $d A$ sobre a superfície do detector de germânio

$$
\mathrm{dA}=\operatorname{RdR} \mathrm{d} \psi
$$

expresso em coordenadas polares com o raio $R$ contado a partir da origem, no centro da face superior do detector, e como ângulo azimutal $\psi$, sendo contado a partir da mesma referência escolhida para $\theta$.

O ângulo sólido $\mathrm{d} \Omega$ com que o ponto $P$ enxerga o elemento de área $d A$ é dado por

$$
\mathrm{d} \Omega=\frac{\mathrm{d} A \cos \alpha}{\mathrm{L}^{2}}
$$

onde $L$ é a distância de $P$ ao centro de $d A$ e $\alpha$ é o ângulo definido entre a normal de $d A$ e a direção definida por L. Substituindo os parâmetros do arranjo experimental tem-se que

$$
\mathrm{d} \Omega=\frac{\left(z+e_{1}+E+e_{2}\right)}{\left(\left(z+e_{1}+E+e_{2}\right)^{2}+r^{2}+R^{2}-2 r R \cos (\psi-\theta)\right)^{\frac{3}{2}}} R d R d \psi
$$

Sendo $C_{0}$ a atividade total da fonte de chumbo radioativo, a atividade devida à solução contida dentro do elemento de volume centrado em $P$ é 


$$
C=\frac{C_{0}}{\pi a^{2} h} r d r d \theta d z
$$

e a atividade emitida por esse elemento de volume por unidade de ângulo sólido é

$$
C^{\prime}=\frac{C_{0}}{4 \pi^{2} a^{2} h} r d r d \theta d z
$$

Sendo

$$
\ell=\frac{E}{z+e_{1}+E+e_{2}} \sqrt{\left(z+e_{1}+E+e_{2}\right)^{2}+r^{2}+R^{2}-2 r R \cos (\psi-\theta)}
$$

a fração da distância $L$ correspondente ao interior da amostra, ou padrão, a intensidade da radiação primária emitida pelo elemento de volume $d V$ em torno do ponto $P$ e que atinge $d A$ é

$$
d l=\frac{C_{0} r d r d \theta d z}{4 \pi^{2} a^{2} h} \cdot \frac{e^{-\mu \frac{E}{z+e_{1}+E+e_{2}}} \sqrt{\left(z+e_{1}+E+e_{2}\right)^{2}+r^{2}+R^{2}-2 r R \cos (\psi-\theta)}}{\left(z+e_{1}+E+e_{2}\right) R} d R d \psi
$$

onde $\mu$ é o coeficiente de atenuação linear da amostra.

Integrando sobre a superfície do detector

$$
\begin{aligned}
& \mathrm{I}(\mathrm{z}, \mathrm{r}, \theta)=\frac{\mathrm{C}_{0} r d r d \theta d z}{4 \pi^{2} \mathrm{a}^{2} \mathrm{~h}} . \\
& \int_{0}^{\mathrm{A}} \int_{\theta}^{\theta+2 \pi} \frac{\mathrm{e}^{-\mu \frac{\mathrm{E}}{\mathrm{z+e_{1 } + E + e _ { 2 }}} \sqrt{\left(z+\mathrm{e}_{1}+\mathrm{E}_{+} \mathrm{e}_{2}\right)^{2}+\mathrm{r}^{2}+\mathrm{R}^{2}-2 \mathrm{rRcos}(\psi-\theta)}}\left(\mathrm{z}+\mathrm{e}_{1}+\mathrm{E}+\mathrm{e}_{2}\right) \mathrm{R}}{\left(\left(\mathrm{z}+\mathrm{e}_{1}+\mathrm{E}+\mathrm{e}_{2}\right)^{2}+\mathrm{r}^{2}+\mathrm{R}^{2}-2 \mathrm{rR} \cos (\psi-\theta)\right)^{\frac{3}{2}}} \mathrm{dR} d \psi(\mathrm{A} .8)
\end{aligned}
$$

obtém-se a intensidade da radiação primária emitida pelo elemento de volume em torno do ponto $P$ que atinge a superfície do detector. 
Integrando sobre o volume da fonte

$$
I=\frac{C_{0}}{4 \pi^{2} a^{2} h} \cdot \int_{0}^{2 \pi} \int_{e_{1}+E+e_{2}}^{h+e_{1}+E^{+} e_{2}} \int_{0}^{a} \int_{0}^{A} \int_{\theta}^{\theta+2 \pi} \frac{e^{-\mu \frac{E}{\zeta} \sqrt{\zeta^{2}+r^{2}+R^{2}-2 r R \cos (\psi-\theta)}} \zeta r R}{\left(\zeta^{2}+r^{2}+R^{2}-2 r R \cos (\psi-\theta)\right)^{\frac{3}{2}}} d \psi d R d r d \zeta d \theta
$$

onde $\zeta=z+e_{1}+E+e_{2}$.

Uma vez que na integração em relação a $\psi$ o ângulo azimutal $\theta$ é mantido fixo e uma vez que a fonte de ${ }^{210} \mathrm{~Pb}$ é homogênea, pode-se definir

$$
\Delta=\psi-\theta
$$

cuja substituição em A.9 e a integração em relação a $\theta$ leva à equação 4.1

$$
I=\frac{C_{0}}{2 \pi a^{2} h} \int_{e_{1}+E+e_{2}}^{h+e_{1}+E+e_{2}} \int_{0}^{a} \int_{0}^{A} \int_{0}^{2 \pi} \frac{e^{-\mu \frac{E}{\zeta} \sqrt{\zeta^{2}+r^{2}+R^{2}-2 r R \cos \Delta}} \zeta r R}{\left(\zeta^{2}+r^{2}+R^{2}-2 r R \cos \Delta\right)^{\frac{3}{2}}} d \Delta d R d r d \zeta
$$

\section{A.2 A aproximação de fonte linear de radiação}

Quando o raio a da fonte radioativa é muito pequeno em comparação com as dimensões da amostra, ou do padrão, e do detector de germânio, pode-se fazer uma abstração representada por uma fonte linear de radiação posta sobre a amostra e coincidindo no espaço com os eixos da amostra e do detector. A figura A.2 representa o modelo simplificado.

Nesse modelo, o ângulo sólido $d \Omega$ com que um ponto $P$ sobre a fonte sobre enxerga um elemento de área sobre a superfície do detector é

$$
d \Omega=\frac{\left(z+e_{1}+E+e_{2}\right) R d R d \theta}{\left(\left(z+e_{1}+E+e_{2}\right)^{2}+R^{2}\right)^{\frac{3}{2}}}
$$




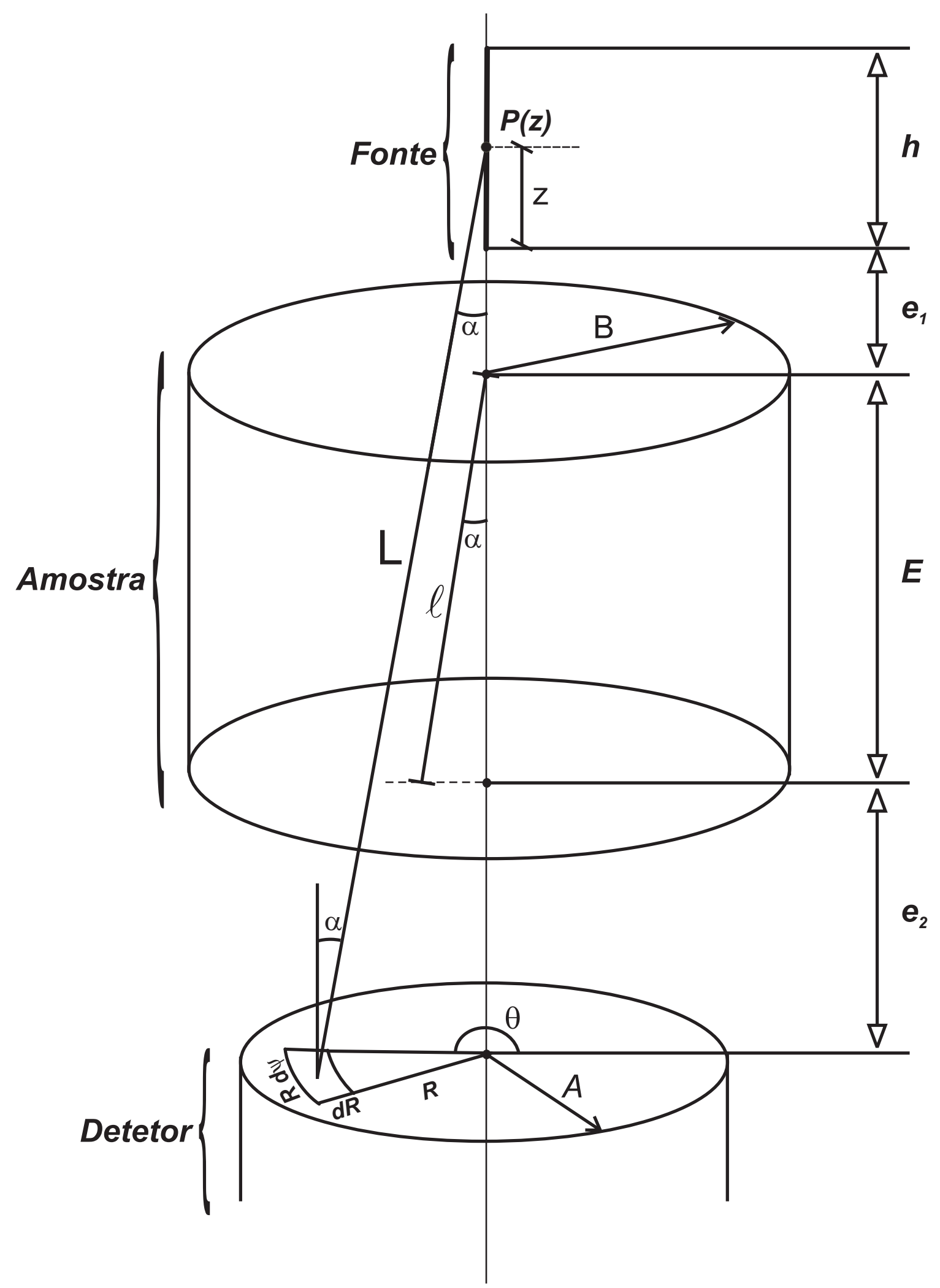

Figura A.2: Modelo geométrico com uma aproximação linear para a radiação primária incidente sobre a superfície do detector. 
Definindo, por conveniência do desenvolvimento, uma nova variável

$$
y=\frac{R}{z+e_{1}+E+e_{2}}
$$

o ângulo sólido $\mathrm{d} \Omega$ possa ser escrito

$$
\mathrm{d} \Omega=\frac{\mathrm{ydyd} \theta}{\left(\mathrm{y}^{2}+1\right)^{\frac{3}{2}}}
$$

Sendo $\mathrm{C}_{0}$ a atividade total da fonte de chumbo radioativo, a atividade emitida por um elemento de comprimento $d z$ centrado em $P$ da fonte por unidade de ângulo sólido é

$$
C^{\prime}=\frac{C_{0} d z}{4 \pi h}
$$

sendo

$$
\begin{aligned}
\ell & =\frac{E}{z+e_{1}+E+e_{2}} \sqrt{R^{2}+\left(z+e_{1}+E+e_{2}\right)^{2}} \\
& =E \sqrt{y^{2}+1}
\end{aligned}
$$

a fração da distância entre o ponto $P$ da fonte radioativa e o elemento de área do detector, que corresponde ao interior da amostra. A intensidade da radiação primária emitida pelo elemento de comprimento e que atinge $d A$ é

$$
\mathrm{dl}=\frac{\mathrm{C}_{0} \mathrm{dz}}{4 \pi \mathrm{h}} \cdot \frac{\mathrm{e}^{-\mu \mathrm{E} \sqrt{\mathrm{y}^{2}+1}}}{\left(\mathrm{y}^{2}+1\right)^{\frac{3}{2}}} \mathrm{ydy} d \theta
$$

e a intensidade da radiação primária que atinge a superfície do detector é 


$$
\mathrm{I}(\mathrm{z})=\frac{\mathrm{C}_{0} \mathrm{dz}}{2 \mathrm{~h}} \int_{0}^{\frac{\mathrm{A}}{\mathrm{z+e_{1 } + \mathrm { E } + \mathrm { e } _ { 2 }}}} \frac{\mathrm{e}^{-\mu \mathrm{E} \sqrt{\mathrm{y}^{2}+1}}}{\left(\mathrm{y}^{2}+1\right) \sqrt{\mathrm{y}^{2}+1}} \mathrm{ydyd} \theta
$$

Definindo uma nova variável

$$
t=\mu E \sqrt{y^{2}+1}
$$

a intensidade da radiação primária sobre o detector passa a ser escrita como

$$
\mathrm{I}(\mathrm{z})=\frac{\mathrm{C}_{0} \mathrm{dz}}{2 \mathrm{~h}} \mu \mathrm{E} \int_{\mu \mathrm{E}}^{\mu \mathrm{E} \sqrt{\frac{\mathrm{A}^{2}}{\left(\mathrm{z}+\mathrm{e}_{1}+\mathrm{E}+\mathrm{e}_{2}\right)^{2}}+1}} \frac{\mathrm{e}^{-\mathrm{t}}}{\mathrm{t}^{2}} \mathrm{dt}
$$

Integrando $I(z)$ por partes

$$
\mathrm{I}(\mathrm{z})=\frac{\mathrm{C}_{0} \mathrm{dz}}{2 \mathrm{~h}} \mu \mathrm{E}\left(\frac{\mathrm{e}^{-\mu \mathrm{E}}}{\mu \mathrm{E}}-\frac{\mathrm{e}^{-\mu \mathrm{E} \sqrt{\frac{\mathrm{A}^{2}}{\left(\mathrm{z}+\mathrm{e}_{1}+\mathrm{E}+\mathrm{e}_{2}\right)^{2}}+1}}}{\mu \mathrm{E} \sqrt{\frac{\mathrm{A}^{2}}{\left(\mathrm{z}+\mathrm{e}_{1}+\mathrm{E}+\mathrm{e}_{2}\right)^{2}}+1}}-\int_{\mu \mathrm{E}}^{\mu \sqrt{\frac{\mathrm{A}^{2}}{\left(\mathrm{z}+\mathrm{e}_{1}+\mathrm{E}+\mathrm{e}_{2}\right)^{2}}+1}} \frac{\mathrm{e}^{-\mathrm{t}}}{\mathrm{t}} \mathrm{dt}\right)
$$

Lembrando da definição da função (ABRAMOWITZ; STEGUN, 1965)

$$
E_{1}=\int_{x}^{\infty} \frac{e^{-t}}{t} d t
$$

a intensidade da radiação primária proveniente do ponto $P$ que atinge a superfície do detector é

$$
\mathrm{I}(\mathrm{z})=\frac{\mathrm{C}_{0} \mathrm{dz}}{2 \mathrm{~h}} \mu \mathrm{E}\left(\frac{\mathrm{e}^{-\mu \mathrm{E}}}{\mu \mathrm{E}}-\frac{\mathrm{e}^{-\mu \mathrm{E} \sqrt{\frac{\mathrm{A}^{2}}{\left(\mathrm{z}+\mathrm{e}_{1}+\mathrm{E}_{\mathrm{e}}\right)^{2}}+1}}}{\mu \mathrm{E} \sqrt{\frac{\mathrm{A}^{2}}{\left(\mathrm{z}+\mathrm{e}_{1}+\mathrm{E}+\mathrm{e}_{2}\right)^{2}}+1}}-\mathrm{E}_{1}(\mu \mathrm{E})+\mathrm{E}_{1}\left(\mu \mathrm{E} \sqrt{\frac{\mathrm{A}^{2}}{\left(\mathrm{z}+\mathrm{e}_{1}+\mathrm{E}+\mathrm{e}_{2}\right)^{2}}+1}\right)\right)
$$


A intensidade total da radiação primária sobre a superfície do detector é

$\mathrm{I}(\mathrm{z})=\frac{\mathrm{C}_{0} \mu \mathrm{E}}{2 \mathrm{~h}} \int_{0}^{\mathrm{h}}\left(\frac{\mathrm{e}^{-\mu \mathrm{E}}}{\mu \mathrm{E}}-\frac{\mathrm{e}^{-\mu \mathrm{E} \sqrt{\frac{\mathrm{A}^{2}}{\left(\mathrm{z}+\mathrm{e}_{1}+\mathrm{E}_{\mathrm{e}}\right)^{2}}+1}}}{\mu \mathrm{E} \sqrt{\frac{\mathrm{A}^{2}}{\left(z+\mathrm{e}_{1}+\mathrm{E}_{\mathrm{e}} \mathrm{e}_{2}\right)^{2}}+1}}-\mathrm{E}_{1}(\mu \mathrm{E})+\mathrm{E}_{1}\left(\mu \mathrm{E} \sqrt{\frac{\mathrm{A}^{2}}{\left(\mathrm{z}+\mathrm{e}_{1}+\mathrm{E}+\mathrm{e}_{2}\right)^{2}}+1}\right)\right) \mathrm{dz}$

o que corresponde à equação 4.2. Na realidade, essa equação está escrita, no capítulo 4, em função da variável $\zeta$ definida como

$$
\zeta=z+e_{1}+E+e_{2}
$$

No caso do coeficiente de atenuação linear $\mu$ ser nulo, a equação $I(z)$ se reduz a

$$
\begin{aligned}
& \mathrm{I}(\mathrm{z}, \mu=0)=\frac{\mathrm{C}_{0}}{2 \mathrm{~h}} \int_{0}^{\mathrm{h}}\left(1-\frac{1}{\sqrt{\frac{\mathrm{A}^{2}}{\left(\mathrm{z}+\mathrm{e}_{1}+\mathrm{E}+\mathrm{e}_{2}\right)^{2}}+1}}\right) \mathrm{dz} \\
& =\frac{C_{0}}{2 h}\left(h-\sqrt{A^{2}+\left(h+e_{1}+E+e_{2}\right)^{2}}+\sqrt{A^{2}+\left(e_{1}+E+e_{2}\right)^{2}}\right)
\end{aligned}
$$

\section{A.2.1 Fórmulas para o cálculo de $E_{1}(x)$}

A função $E_{1}(x)$, equação $A .19$ pode ser aproximada, para valores inferiores ou iguais a 1, pela expansão em série (ABRAMOWITZ; STEGUN, 1965)

$$
E_{1}(x)+\ln (x)=a_{0}+a_{1} x+a_{2} x^{2}+a_{3} x^{3}+a_{4} x^{4}+a_{5} x^{5}+\epsilon(x)
$$

onde os coeficientes $a_{n}$ são dados na tabela A.1, com $|\epsilon(x)|<2 \cdot 10^{-7}$.

Para argumentos iguais ou superiores a $1, E_{1}(x)$ pode ser calculada pela expansão racional (ABRAMOWITZ; STEGUN, 1965): 


$$
x e^{x} E_{1}(x)=\frac{x^{4}+b_{1} x^{3}+b_{2} x^{2}+b_{3} x+b_{4}}{x^{4}+c_{1} x^{3}+c_{2} x^{2}+c_{3} x+c_{4}}+\epsilon(x)
$$

$\operatorname{com}|\epsilon(\mathrm{x})|<2 \cdot 10^{-8}$.

Os coeficiente $b_{n}$ e $c_{n}$ utilizados na integração são fornecidos na tabela A.1.

Tabela A.1: Coeficientes da equações A.23 e A.24.

\begin{tabular}{rrr}
\hline $\mathbf{E}_{\mathbf{1}}(\mathbf{x}) \leq \mathbf{1}$ & \multicolumn{2}{c}{$\mathbf{E}_{\mathbf{1}}(\mathbf{x}) \geq \mathbf{1}$} \\
\hline $\mathrm{a}_{0}=-0,57721$ & $\mathrm{~b}_{1}=8,57332$ & $\mathrm{c}_{1}=9,57332$ \\
$\mathrm{a}_{1}=0,99999$ & $\mathrm{~b}_{2}=18,05901$ & $\mathrm{c}_{2}=25,63295$ \\
$\mathrm{a}_{2}=-0,24991$ & $\mathrm{~b}_{3}=8,63476$ & $\mathrm{c}_{3}=21,09965$ \\
$\mathrm{a}_{3}=0,05519$ & $\mathrm{~b}_{4}=0,26777$ & $\mathrm{c}_{4}=3,95849$ \\
$\mathrm{a}_{4}=-0,00976$ & & \\
$\mathrm{a}_{5}=0,00107$ & & \\
\hline
\end{tabular}




\section{APÊNDICE B - Modelo teórico para a correção do efeito de auto-absorção da radiação do ${ }^{210} \mathrm{~Pb}$ - parte II}

\section{B.1 O desenvolvimento da equação 4.5}

A correção do efeito de auto-absorção é feita através do modelo representado pela equação 4.5. Essa equação é deduzida, levando-se em conta a geometria de detecção esquematizada na figura B.1. A amostra, ou o padrão de radioatividade, com altura $E$ e raio a, é posto sobre o detector fazendo com que o eixo de ambos coincidam. $\mathrm{O}$ espaço entre a superfície do detector e a base da amostra,o ou padrão, é $e_{2}$, incluindo a espessura dos diferentes invólucros.

A equação 4.5 é deduzida considerando-se, também que apenas a radiação primária proveniente do ${ }^{210} \mathrm{~Pb}$ disperso em amostras e padrões contribui para a formação do pico de absorção total de 46,5 keV característico desse radionuclídeo. O invólucro da amostra, ou do padrão, e o ar contido entre a amostra e o detector não atenuam, nesse modelo, a radiação- $\gamma$.

Considere um ponto $P$ no interior de uma amostra identificado pelas suas coordenadas cilíndricas $z$, contada a partir da base da amostra, a distância do eixo da amostra $r$ e o ângulo azimutal $\theta$, contado a partir de uma origem definida de forma arbitrária. Considere também um elemento de área

$$
d A=R d R d \psi
$$




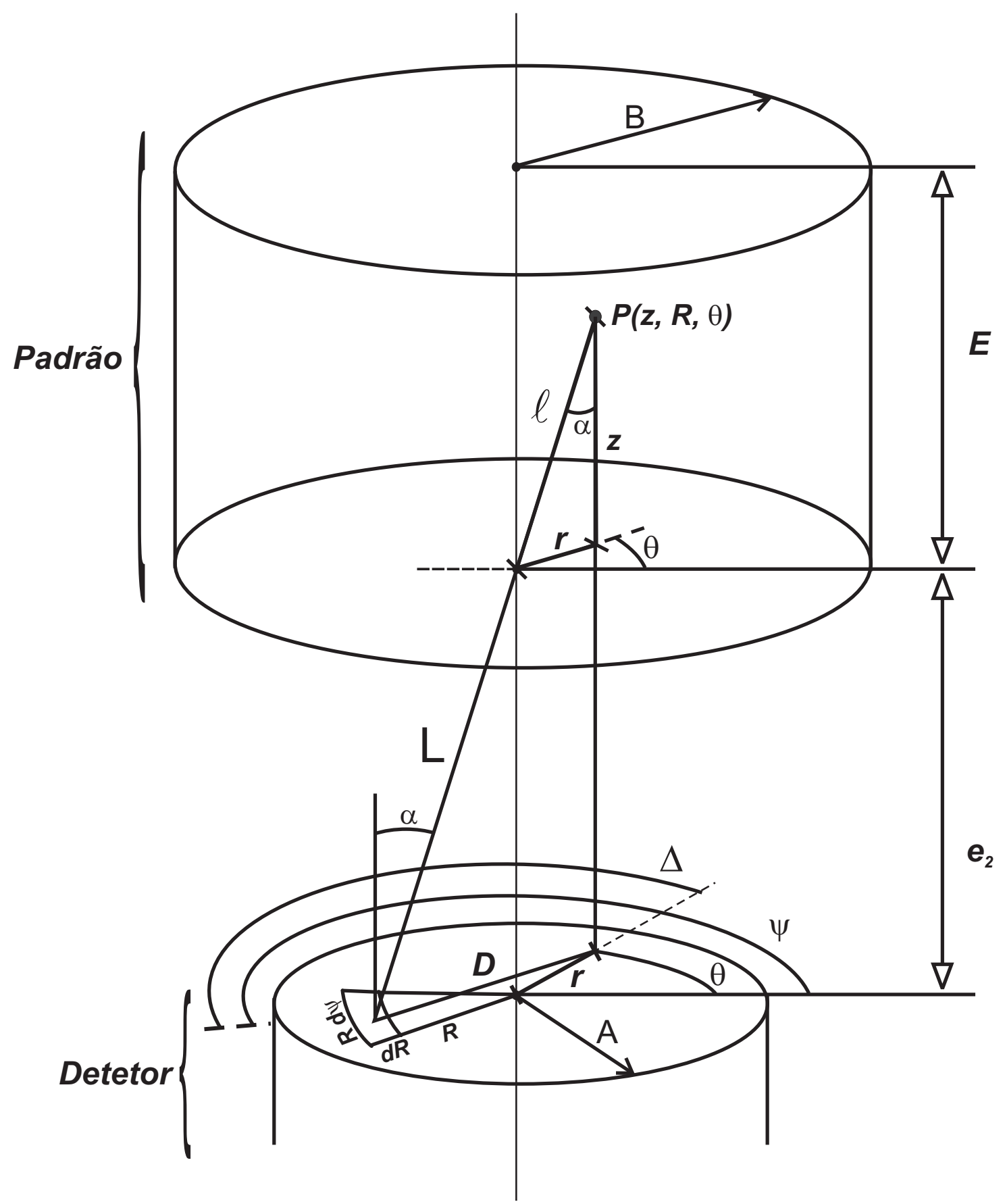

Figura B.1: Geometria para o ângulo sólido de um fóton incidente sobre a superfície do detector quando emitido por um padrão radioativo secundário sobre o detector. 
definido sobre a face circular do detector e centrado em um ponto $(P)$, identificado pelas suas coordenadas polares, raio vetor $R$ e ângulo azimutal $\psi$, medido a partir da mesma origem definida para $\theta$.

Sendo $\alpha$ o ângulo entre a normal do elemento de área e a direção definida pelo ponto $P$ e pelo centro do elemento de área, o ângulo sólido com que $P$ enxerga $d A$ é dado por

$$
\mathrm{d} \Omega=\frac{\cos \alpha \operatorname{RdR} \mathrm{d} \psi}{\mathrm{L}^{2}}
$$

sendo $L$ a distância entre $P$ e $P^{\prime}$. Da figura B.1 tem-se que

$$
\cos \alpha=\frac{\mathrm{z}+\mathrm{e}_{2}}{\mathrm{~L}}
$$

e

$$
L=\left(\left(z+e_{2}\right)^{2}+r^{2}+R^{2}-2 r R \cos (\psi-\theta)\right)^{\frac{3}{2}}
$$

de onde

$$
\mathrm{d} \Omega=\frac{\left(z+e_{2}\right) R d R d \psi}{\left(\left(z+e_{2}\right)^{2}+r^{2}+R^{2}-2 r R \cos (\psi-\theta)\right)^{\frac{3}{2}}}
$$

Sendo a atividade total da amostra $\mathrm{C}_{0}$, o fluxo de radiação primária, proveniente de um elemento de volume centrado em $P$ e que atinge $d A$ é:

$$
C=\frac{C_{0} r d r d \theta d z}{4 \pi^{2} B^{2} E} e^{-\mu \ell} d \Omega
$$

onde 


$$
\ell=\frac{z}{z+e_{2}} \sqrt{\left(z+e_{2}\right)^{2}+r^{2}+R^{2}-2 r R \cos (\psi-\theta)}
$$

é a fração da distância $L$ contida dentro do volume da amostra e $\mu$ é o seu coeficiente de atenuação linear. Das equações B.5, B.6 e B.7

$$
C=\frac{C_{0} r d r d \theta d z}{4 \pi^{2} B^{2} E} \cdot \frac{e^{-\mu \frac{z}{z+e_{2}} \sqrt{\left(z+e_{2}\right)^{2}+r^{2}+R^{2}-2 r R \cos (\psi-\theta)}}}{\left(\left(z+e_{2}\right)^{2}+r^{2}+R^{2}-2 r R \cos (\psi-\theta)\right)^{\frac{3}{2}}}\left(z+e_{2}\right) R d R d \psi
$$

Integrando sobre a superfície do detector e sobre o volume da amostra, a intensidade total da radiação primária que atinge o detector é dada por

$$
I=\frac{C_{0}}{4 \pi^{2} B^{2} E} \int_{0}^{2 \pi} d \theta \int_{0}^{E} d z \int_{0}^{B} r d r \int_{\theta}^{\theta+2 \pi} d \psi \int_{0}^{A} \frac{e^{-\mu \frac{z}{z+e_{2}} \sqrt{\left(z+e_{2}\right)^{2}+r^{2}+R^{2}-2 r R \cos (\psi-\theta)}}\left(z+e_{2}\right) R}{\left(\left(z+e_{2}\right)^{2}+r^{2}+R^{2}-2 r R \cos (\psi-\theta)\right)^{\frac{3}{2}}} d R
$$

Como na integração em relação a $\psi, \theta$ é mantido constante e como a distribuição do radionuclídeo ${ }^{210} \mathrm{~Pb}$ é homogênea dentro do volume da amostra, pode-se definir uma nova variável

$$
\Delta=\psi-\theta
$$

O que leva à equação 4.5

$$
I=\frac{C_{0}}{2 \pi B^{2} E} \int_{0}^{E} d z \int_{0}^{B} r d r \int_{0}^{2 \pi} d \Delta \int_{0}^{A} \frac{e^{-\mu \frac{z}{z+e_{2}} \sqrt{\left(z+e_{2}\right)^{2}+r^{2}+R^{2}-2 r R \cos (\Delta)}}}{\left(\left(z+e_{2}\right)^{2}+r^{2}+R^{2}-2 r R \cos (\Delta)\right)^{\frac{3}{2}}}\left(z+e_{2}\right) R d R
$$




\section{B.2 Limitação do método - crítica do modelo}

Ao se escrever as equações 4.1, 4.2 e 4.5 considerou-se implicitamente que apenas a radiação primária contribuiria para a área do pico de absorção total do ${ }^{210} \mathrm{~Pb}$ com 46,5 keV de energia. Todo fóton- $\gamma$ que tenha sofrido interações com a matéria é considerado, no modelo adotado, como sendo totalmente absorvido por efeito fotoelétrico ou espalhado por efeito Compton, de forma que a energia dos fótons espalhados fosse suficientemente inferior a 46,5 keV, não contribuindo com contagens na área do pico de absorção total do ${ }^{210} \mathrm{~Pb}$. A tabela B.2 apresenta a energia do fótons espalhados por efeito Compton, considerando que a energia inicial dos fótons é 46,5 keV, para ângulos de espalhamento variando de 0 a $90^{\circ}$.

Tabela B.1: Energia dos fótons espalhados por efeito Compton como função do ângulo de espalhamento, admitindo um feixe de fótons incidente com 46,5 keV de energia.

\begin{tabular}{cc}
\hline Ângulo de espalhamento & Energia do fóton espalhado (keV) \\
\hline $0^{\circ}$ & 46,5 \\
$5^{\circ}$ & 46,5 \\
$10^{\circ}$ & 46,4 \\
$15^{\circ}$ & 46,4 \\
$20^{\circ}$ & 46,2 \\
$25^{\circ}$ & 46,1 \\
$30^{\circ}$ & 45,9 \\
$35^{\circ}$ & 45,7 \\
$40^{\circ}$ & 45,5 \\
$45^{\circ}$ & 45,3 \\
$50^{\circ}$ & 45,0 \\
$55^{\circ}$ & 44,8 \\
$60^{\circ}$ & 44,5 \\
$65^{\circ}$ & 44,2 \\
$70^{\circ}$ & 43,9 \\
$75^{\circ}$ & 43,6 \\
$80^{\circ}$ & 43,2 \\
$85^{\circ}$ & 42,9 \\
$90^{\circ}$ & 42,6 \\
\hline
\end{tabular}

Considerando que o valor médio da largura à meia altura (FWHM) do pico de absorção total com $46,5 \mathrm{keV}$ de energia do ${ }^{210} \mathrm{~Pb}$, medido nas 21 amostras de solo, é de $(1,02 \pm 0,06) \mathrm{keV}$, a incerteza correspondendo a um desvio padrão, fótons espa- 
Ihados com ângulos de até $40^{\circ}$ podem contribuir para a área do pico de absorção total. O resultado é um empilhamento de contagens (pile-up) que não é levado em consideração nos modelos utilizados.

A probabilidade de que os fótons provenientes do decaimento radioativo do ${ }^{210} \mathrm{~Pb}$ sofram espalhamento Compton nas matrizes estéreis do quartzo moído e do carbonato de cálcio dos padrões de radioatividade e provavelmente nas amostras é considerável. O carbono, o oxigênio e o silício, por exemplo, têm números atômicos 6,8 e 14 respectivamente. Para fótons com energias entre $40 \mathrm{keV}$ e $50 \mathrm{keV}$ as probabilidades de absorção por efeito fotoelétrico e de espalhamento Compton são semelhantes (EVANS, 1955). O cálcio, por sua vez, tem número atômico 20 e, para energias entre 40 keV e 50 keV a absorção por efeito fotoelétrico é o processo dominante de interação com a radiação.

Os resultados de atividade de ${ }^{210} \mathrm{~Pb}$ obtidos para as amostras de solo, utilizando um padrão de radioatividade com uma matriz de quartzo moído e um padrão de radioatividade com matriz de carbonato de cálcio, sugerem, mas não demonstram, que o efeito de empilhamento seja, pelo menos, parcialmente cancelado durante o processo de cálculo das atividades descrito no capítulo 4. 